\title{
Mitochondrial Dysfunction: The Road to Alpha-Synuclein Oligomerization in PD
}

\author{
A. R. Esteves, ${ }^{1}$ D. M. Arduíno, ${ }^{1}$ D. F. F. Silva, ${ }^{1}$ C. R. Oliveira, ${ }^{1,2}$ \\ and S. M. Cardoso ${ }^{1,2}$ \\ ${ }^{1}$ Centro de Neurociências e Biologia Celular, Universidade de Coimbra, 3004 Coimbra, Portugal \\ ${ }^{2}$ Faculdade de Medicina, Universidade de Coimbra, 3000 Coimbra, Portugal \\ Correspondence should be addressed to S. M. Cardoso, smacardoso@yahoo.com
}

Received 20 September 2010; Revised 21 December 2010; Accepted 27 December 2010

Academic Editor: David K. Simon

Copyright ( 2011 A. R. Esteves et al. This is an open access article distributed under the Creative Commons Attribution License, which permits unrestricted use, distribution, and reproduction in any medium, provided the original work is properly cited.

\begin{abstract}
While the etiology of Parkinson's disease remains largely elusive, there is accumulating evidence suggesting that mitochondrial dysfunction occurs prior to the onset of symptoms in Parkinson's disease. Mitochondria are remarkably primed to play a vital role in neuronal cell survival since they are key regulators of energy metabolism (as ATP producers), of intracellular calcium homeostasis, of $\mathrm{NAD}^{+} / \mathrm{NADH}$ ratio, and of endogenous reactive oxygen species production and programmed cell death. In this paper, we focus on mitochondrial dysfunction-mediated alpha-synuclein aggregation. We highlight some of the findings that provide proof of evidence for a mitochondrial metabolism control in Parkinson's disease, namely, mitochondrial regulation of microtubule-dependent cellular traffic and autophagic lysosomal pathway. The knowledge that microtubule alterations may lead to autophagic deficiency and may compromise the cellular degradation mechanisms that culminate in the progressive accumulation of aberrant protein aggregates shields new insights to the way we address Parkinson's disease. In line with this knowledge, an innovative window for new therapeutic strategies aimed to restore microtubule network may be unlocked.
\end{abstract}

\section{Introduction}

Parkinson's disease (PD) was first associated with the loss of the brown pigment neuromelanin from the substantia nigra. Later, it was postulated that the progressive loss of dopamineproducing cells in the substantia nigra pars compacta of the ventral midbrain caused PD symptomatology. In addition, $\mathrm{PD}$ is also associated with the presence of intracytoplasmatic inclusions known as Lewy Bodies (LBs), which are composed largely of alpha-synuclein (alpha-syn). The function of alpha-syn is still unclear, but its involvement in PD pathogenesis is further indicated by a subset of familial cases of PD that carry either a missense mutation in snca (alphasyn) gene or have a duplication or triplication of alpha-syn locus [1-4].

To date, mutations in at least $16 \mathrm{PD}$-genetic loci (PARK) have been linked to the pathogenesis of PD [5]. The discovery of these genes in which mutations cause early or late-onset forms of PD has greatly accelerated research progress. These include pink-1, dj-1, parkin, lrrk2, uchl-1, omi/htra2, atp13a2, pla2g6, fbx07, and snca, as previously mentioned. OMI/HTRA2, PINK-1, DJ-1, LRRK2, and Parkin are either mitochondrial proteins or are associated with mitochondria and may be involved in pathways related to oxidative stress and free radical damage. Pink-1 encodes a putative serine/threonine kinase with a mitochondrial targeting sequence [6], and DJ-1 is a redox sensor which is involved in the response to oxidative stress [7]. Although Parkin is a putative E3 ligase in the ubiquitin proteasome system that localizes predominantly to the cytosol, it also associates with the mitochondrial outer membrane [8]. Most recently mutations affecting the mitochondrial serine protease OMI/HTRA2 have been linked to increased risk of PD [9]. Mice entirely lacking expression of omi/htra2 due to targeted deletion of its gene, Prss25, show a decrease in a population of neurons in the striatum and have a parkinsonian phenotype that leads to death of the mice around 30 days after birth [10]. In addition, loss of Omi protease 
activity increases the susceptibility of mitochondria to induce the permeability transition pore [11]. LRRK2 is a kinase that colocalizes with the mitochondrial outer membrane [12] and may regulate the response to mitochondrial inhibitors [13].

PD etiopathogenesis includes genetic, epigenetic, and environmental factors. However, in sporadic cases of PD, in which ageing is the major risk factor, the initial event that causes the pathology is not clear. Nevertheless, it is known that several mechanisms are involved in the development of PD pathogenesis such as mitochondrial dysfunction, oxidative damage, autophagic alterations, proteasome impairment, microtubule network disruption, and protein aggregation. Efforts have been made in order to discover what triggers the pathogenesis of $\mathrm{PD}$ that culminates in the death of a specific group of neurons, dopaminergic neurons. Nowadays several studies highlight mitochondrial dysfunction as the leading event. In this paper, we will underscore mitochondrial-mediated mechanisms and their involvement in PD pathogenesis.

\section{Parkinson's Disease: A Mitochondrial Disorder?}

There is mounting evidence for mitochondria involvement in neurodegenerative disorders, including PD. Mitochondria play a fundamental role in energy metabolism; their primary function is to provide energy (in the form of ATP) for intracellular metabolic pathways. Mitochondrial electron transport chain deficiencies are thought to underlie defects in energy metabolism and have been implicated in the neurodegenerative process. Moreover, brain cells are highly dependent on the oxidative phosphorylation (OXPHOS) machinery in mitochondria, which involves the respiratory complexes [14].

The first evidence of mitochondrial dysfunction involvement in the pathogenesis of PD emerged following the observation that accidental exposure of drug abusers to 1-methyl-4-phenyl-1,2,3,4-tetrahydropyridine (MPTP), an inhibitor of complex I (NADH/ubiquinone oxidoreductase) of the mitochondrial electron transport chain, induced parkinsonism [15]. Moreover, Parker and colleagues found a significant reduction of complex I activity in platelet mitochondria, purified from patients with idiopathic PD [16]. Evidence for dysfunctional mitochondrial metabolism in PD arises from studies performed in the substantia nigra of postmortem PD brain showing a deficient complex I activity $[17,18]$. Additionally, a selective decrease in complex I subunits was demonstrated in PD brain [19]. This was corroborated by Keeney and coworkers that reported some abnormalities in the assembly and oxidation of complex I subunits in mitochondria from PD patients cortex [20]. Complex I deficiency has been also described in other PD tissues, namely, in peripheral cell models such as, platelets, lymphoblasts, muscle, and fibroblasts [21-26]. More recently, a specific complex I deficit was detected in highly purified mitochondria from the frontal cortex of PD patients [27]. To address mitochondrial involvement in the pathogenesis of PD, King and Attardi, in 1989, succeeded in repopulating human cells depleted from mtDNA, a Rho0 cell line, with mitochondrial genes from donor cells [28]. Human cell lines (SH-SY5Y neuroblastoma or NT2 teratocarcinoma cells) depleted of mtDNA were fused with either control or PD platelets that contain mtDNA, but no nuclear DNA. Several authors showed that these cybrids harbour a complex I defect [29-32] and have a decrease in ATP levels and loss of mitochondrial membrane potential [29]. Further support for mitochondrial involvement in PD comes from studies using toxins [33-35] like rotenone, paraquat, and maneb that appear to reproduce some of the features of PD in animal models. Although several of these toxins are mitochondrial, they induce nigrostriatal lesions motor and postural deficits by different mechanisms of action [36-44].

High levels of mtDNA deletions have been observed in dopaminergic neurons from the substantia nigra of postmortem human brains from aged individuals and idiopathic PD patients $[45,46]$. mtDNA deletions in these neurons were correlated with a decrease in cytochrome c oxidase activity, one of the key enzymes of electron transport chain. This suggests that accumulation of mtDNA deletions in dopaminergic neurons from substantia nigra above a certain threshold can cause mitochondrial defects associated with PD. It is well established that mtDNA accumulates mutations during the ageing process which correlates with decline in mitochondrial function in late-onset PD. TFAM is a phylogenetically conserved protein and is imported to mitochondria which is essential for mtDNA maintenance and directly regulates mtDNA copy number and is absolutely required for transcription initiation at mtDNA promoters [47-49]. The most compelling evidence regarding TFAM involvement in PD was reported by Ekstrand and colleagues showing that the conditional and selective inactivation of both TFAM alleles in substantia nigra of transgenic mice induced respiratory chain deficiency in dopaminergic neurons leading to a Parkinsonism phenotype with adult onset of slowly progressive impairment of motor function accompanied by the formation of inclusions and neuronal death [50]. Taking into consideration the above findings, it was hypothesized that potentially functional polymorphic TFAM variants could influence PD risk depending on haplogroup background. However, Alvarez and coworkers study in 250 patients report no TFAM-mutations/polymorphisms that could contribute to the risk for $\operatorname{PD}[51,52]$. Other enzyme that regulates mtDNA replication and plays an important role in mtDNA maintenance is the mtDNA polymerase gamma 1 (POLG1). This enzyme is a nuclearencoded protein involved in the synthesis, replication, and repair of mtDNA that is imported to mitochondria and localizes in the inner mitochondrial membrane. POLG1 mutations might impair mtDNA replication, which leads to gradual accumulation of multiple mtDNA deletions, resulting in respiratory chain dysfunction [53]. Luoma and colleagues have found that missense mutations of POLG1 cosegregate in patients with a phenotype that includes progressive external ophthalmoplegia and parkinsonism [54, 55]. Moreover, POLG1 mutations have also been described in case studies, in which parkinsonism was part of the clinical spectrum [56]. Deletion of functional ndufs4, a gene 
encoding one of the subunits required for complete assembly and function of complex I, led to abolished complex I activity in midbrain mesencephalic cultures derived from ndufs 4 knockout mice [57]. However, this deletion did not affect the survival of dopaminergic neurons in culture. Nonetheless, studies performed in rats that expressed an enzyme called "alternative NADH dehydrogenase" (Ndi1) in the substantia nigra, showed a reduced toxic effect of MPTP and rotenone $[58,59]$.

2.1. Oxidative Stress: ROS-Related Consequences. Mitochondrial OXPHOS is known to be the major source of ROS. Cells in normal conditions are able to cope with excessive ROS because they are endowed with robust endogenous antioxidant systems. However, when ROS production overwhelms the endogenous antioxidant systems, due to mitochondrial dysfunction, this can potentially damage various types of biomolecules, including proteins, lipids, and nucleic acids. Markers of oxidative stress, such as products of lipid peroxidation, protein oxidation, and oxidation of mtDNA and cytoplasmic RNA, are increased in postmortem samples of substantia nigra in PD brains as compared to controls [60-64]. In PD patient's postmortem substantia nigra, there is evidence for decreased levels of reduced glutathione and altered iron metabolism [65]. Furthermore, proteomic studies revealed that several mitochondrial and ROS scavenging proteins expressed in the substantia nigra of PD patients had oxidative modifications supporting a role of oxidative stress in PD [66]. It is strongly believed that proximity of mtDNA to ROS generation site, the lack of histones, and diminished capacity for DNA repair increase mitochondrial vulnerability to mutations and oxidative stress $[67,68]$. It appears that substantia nigra is more vulnerable to impairments of complex I activity than other brain regions and peripheral blood cells, possibly due to increased levels of iron and to dopamine metabolism [69]. The intracellular auto-oxidation of dopamine generates $\mathrm{H}_{2} \mathrm{O}_{2}$ and dopaminequinone species which will exert cytoxicity in dopaminergic neuronal cells $[70,71]$.

Several papers showed an involvement of oxidative stress in alpha-syn toxicity. Nitration and nitrosylation of proteins and especially of alpha-syn and parkin in PD have been documented [72-74]. Leong and coworkers demonstrated that methionine oxidation of dopamine generates soluble alpha-syn oligomers highlighting the potential role for oxidative stress in modulating alpha-syn aggregation [75]. Interestingly, studies performed in SH-SY5Y cells overexpressing alpha-syn A53T mutant or wild type and in isolated rat brain mitochondria showed that alpha-syn localizes at the mitochondrial membrane, and this interaction of alphasyn with mitochondria causes oxidative modification of mitochondrial components [76].

The involvement of oxidative stress in PD is also corroborated by the fact that two of the PD-related genes, $\mathrm{dj}-1$ and pink-1, have important roles in maintaining the balance between oxidative stress and antioxidant defenses. DJ-1 functions as a redox-sensitive chaperone as well as a sensor for oxidative stress and apparently protects neurons against oxidative stress and cell death. Mutations in this gene are the cause of autosomal recessive early-onset PD [77]. Hayashi and colleagues suggested that DJ-1 is an integral mitochondrial protein that directly plays a role in maintenance of mitochondrial complex I activity [78]. PINK-1 is a serine/threonine protein kinase that localizes to mitochondria. It is thought to protect cells from stressinduced mitochondrial dysfunction. Mutations in this gene cause one form of autosomal recessive early-onset Parkinson disease [6].

Taken together these findings suggest a pivotal role for mitochondrial-mediated oxidative stress in PD pathogenesis.

2.2. Mitochondrial Metabolism: $N A D^{+} / N A D H$ Ratio. Several studies suggest that changes in energy metabolism in the brain are not merely a consequence of neuronal loss but rather a contributory factor to the progression and development of the disease [79-83]. The decrease in mitochondrial bioenergetics capacity and altered redox status is linked through various mechanisms including interconvertible reducing equivalent pool: $\mathrm{NAD}^{+}$and reduced $\beta$-nicotinamide adenine dinucleotide (NADH) [84]. $\mathrm{NAD}^{+}$and NADH are major factors for numerous energy metabolism-associated redox reactions and mitochondrial functions but also calcium homeostasis, ageing, and cell death [85]. Additionally, $\mathrm{NAD}^{+} / \mathrm{NADH}$ ratio is a powerful regulator of glycolysis, TCA cycle, and oxidative phosphorylation. Our group recently observed that $\mathrm{NAD}^{+} / \mathrm{NADH}$ ratio is significantly increased in PD cybrids when compared with CT cybrids (Esteves et al., submitted). By using an oxygen electrode, we observed that although whole cell basal oxygen consumption was comparable between the PD and CT cybrids, the proton leak was increased and maximum respiratory capacity was decreased in the PD cybrids [86].

Multiple families of enzymes catalyze various biochemical reactions by consuming $\mathrm{NAD}^{+}$. Among these are the recent identified sirtuins (SIRTs) that have a catalytic domain characterized by its requirement for $\mathrm{NAD}^{+}$as a cofactor. SIRTs are a family of deacetylase enzymes that are able to remove the acetyl group from $\varepsilon$-amine of lysine and have been found in a wide variety of subcellular locations. So far, in humans there are seven identified SIRTs (SIRT1 to SIRT7) that play a role in a wide variety of important biological processes, including transcriptional silencing, DNA recombination and repair, apoptosis, axonal protection, fat mobilization, and ageing [87]. The deacetylase and ADP ribosylase activity of SIRTs suggests that they could act as metabolic or oxidative sensors, regulating cellular machinery according to the information they receive. Resveratrol, an activator of SIRT1 [88], protected SH-SY5Y cells against dopamine-induced cytotoxicity by reducing intracellular oxidative stress [89]. Additionally, it was shown to exert a neuroprotective effect on 6-OHDA rat model of PD [90] and to significantly protect mice from MPTP-induced motor coordination impairment, hydroxyl radical overloading, and neuronal loss [91]. On the other hand, a work from 2009 showed that SIRT1 overexpression did not exert any neuroprotective effect against neuronal damage induced by MPTP 
in mice [92]. A dramatic reduction in the expression of SIRT1 occurred when an acute stress was induced by addition of several neurotoxins $\left(\mathrm{MPP}^{+}\right.$, rotenone, $\mathrm{KA}$, or $3 \mathrm{NPA}$ ) to the culture medium. However, in human samples of $\mathrm{PD}$ and dementia with LBs, there were no changes in SIRT1 expression [93]. So far, no work has been published regarding SIRT1 involvement in alpha-syn oligomers clearance in PD. In an MPTP-treated primate model of PD, caloric restriction, wich upregulates SIRT1, prevented the function of locomotor function and preserved striatal dopamine [94]. SIRT1 is known to deacetylate approximately a dozen of known substrates, such as peroxisome proliferator-activated receptor gamma coactivator-1 alpha $(\mathrm{PGCl} \alpha)$. $\mathrm{PGCl} \alpha$ is of major importance for PD etiopathogenesis because it plays a central role in the regulation of cellular energy metabolism and stimulates mitochondrial biogenesis. Work from our group demonstrated that PD cybrids with inherent mitochondrial dysfunction have a decrease in SIRT1 activity that was correlated with a decrease in PGC1 $\alpha$ levels indicating that mitochondrial biogenesis is affected in our PD model [86]. However, more studies need to be performed in order to substantiate this data. The role of SIRT2 in neurodegenerative disorders is less established. Nevertheless, North and coworkers provided data revealing that SIRT2 is involved in cell cycle regulation via the deacetylation of $\alpha$-tubulin [95]. More recently, Outeiro and coworkers reported an intriguing connection between SIRT2 and PD that suggested that inhibition of the human SIRT2 rescues cells from alpha-syn-mediated toxicity [96]. The exact mechanism whereby SIRT2 inhibition affects alpha-syn aggregation remains uncertain. One proposed mechanism is through alpha-syn interaction with alphatubulin [97-99]. Moreover, it was shown that PD cybrids have an increased free/polymerized tubulin ratio indicating that microtubule destabilization may mediate alpha-syn oligomers accumulation [98]. Apha-tubulin acetylation is associated with microtubule stabilization, so one possibility is that an increase in SIRT2 activation due to increase in $\mathrm{NAD}^{+}$levels increases alpha-tubulin deacetylation leading to microtubules network disruption which potentiates alphasyn oligomerization (Esteves et al., submitted). So far, little is known about the remaining SIRTs involvement in PD. Overall, SIRTs targeting may be therapeutically beneficial in PD pathogenesis by manipulating the pathways responsible for PD neurodegeneration not only regarding alpha-syn oligomerization but also mitochondrial biogenesis. However, despite exciting data, the feasibility of developing SIRTsbased therapy for PD and other neurodegenerative diseases needs to be demonstrated in animal models, and finally in human trials.

2.3. Calcium Homeostasis Deregulation. Disturbances in calcium homeostasis can affect neuronal functionality since calcium is one of the most important elements in cellular signaling. An increase in cytosolic calcium concentration can arise from two sources: the major intracellular calcium store which is the endoplasmic reticulum and the extracellular space. Moreover, mitochondrial function is based on the ability to uptake calcium and to accumulate it in the matrix, being this process dependent on the mitochondrial membrane potential. The primary role of mitochondrial calcium is the stimulation of OXPHOS [100]; thus, any perturbation in mitochondrial or cytosolic calcium results in profound alteration of cellular function. Rotenone was shown to increase the susceptibility of cells to calcium overload with subsequent cell death in SH-SY5Y neuroblastoma cells [101]. Sheehan and coworkers showed that PD cybrids sequestered less calcium in their mitochondria than CT cybrids, due to their decreased mitochondrial function [102]. Subsequently, our work showed that PD cybrids have a significantly higher concentration of cytosolic calcium as compared to CT cybrids and in addition show less capacity in mitochondrial calcium buffering, indicating that mitochondrial normal function is impaired [103].

In addition, an increased activity of calcium-stimulated phospholipase $A_{2}$ in the putamen is reported to be due to either decreased dopaminergic striatal input or degenerative processes in dopamine nerve terminals [104]. Dopaminergic neurons from substantia nigra express calcium buffering proteins which effectively sequester calcium without using ATP. Expression of the calcium buffering protein, calbindin, reduces vulnerability to mitochondrial toxins [105] and seems to confer resistance to MPTP [106]. Interestingly, dopaminergic neurons that do not express the $\mathrm{Ca}^{2+}$ buffering protein, calbindin-D28k, are selectively lost during PD progression [107]. In addition, dopaminergic neurons that express relatively high levels of another calciumbuffering protein, calretinin, appear to be resistant to degeneration in PD [108].

So far, it has been demonstrated that alpha-syn regulates calcium entry pathways and, consequently, that abnormal alpha-syn levels may promote neuronal damage through deregulation of calcium homeostasis [109].

\section{Mitochondrial Metabolic Control of Cellular Traffic: Microtubules Involvement}

Cytoskeletal injury is likely to be responsible for altered rearrangement and movement of organelles, being a common feature of several neurodegenerative diseases including PD. Microtubules are highly dynamic polar structures that play critical roles in diverse cellular functions. These include cell motility and division, organelle transport, cell morphology, and organization. Intracellular transport of protein and organelle cargo is one of microtubules' most important function, and is an essential requirement for all mammalian cells. In addition, microtubule-mediated transport is crucial to maintain the function and structure of neurons [110]. Microtubules dynamic instability requires an input of energy to undergo polymerization and depolymerization cycles. This dynamic process is extremely regulated and is influenced by many factors, where the concentration of free tubulin is the driving force [111].

Several lines of evidence suggested that microtubules disruption may be involved in PD. In fact, tubulin was shown to colocalize with alpha-syn in LBs. Also, tubulin folding is 
dependent on ATP and GTP hydrolysis, and mitochondrial impairment with subsequent energy failure is one of $\mathrm{PD}$ hallmarks $[112,113]$. Toxins that affect ATP production may affect the tubulin polymerization/depolymerization process leading to an increase in free tubulin. In fact, $\mathrm{MPP}^{+}$, a known complex I inhibitor that induces PD-like symptoms, depolymerizes microtubules in PC12 cells [114, 115]. Later, Cappelletti and coworkers provided the first evidence that microtubules instability is specifically affected by $\mathrm{MPP}^{+}$ [116]. Moreover, rotenone, another complex I inhibitor, was also shown to potentiate microtubules depolymerisation in vivo and in vitro [117] by binding to the colchicine site on tubulin heterodimers [118]. Ren and Feng found that microtubule depolymerization induced by rotenone caused vesicle accumulation in the soma and killed serotonergic neurons through a mechanism dependent on serotonin metabolism in the cytosol [119].

Microtubule depolymerization induces disruption in axonal transport, which leads to an accumulation of damaged organelles, aggregated/misfolded proteins, and vesicles. What happens in dopaminergic neurons is that dopamine leakage from the vesicles to the cytosol promotes an increase in oxidative stress induced by dopamine oxidation which culminates in cell death [120]. Treatment of cotransfected cells or primary mesencephalic neurons with colchicine, vinblastine, or nocodazole reversed alpha-syn-mediated inhibition of DAT activity providing insights for alpha-syn regulation of DAT activity, namely, by tethering the transporter to the microtubular network [121]. Furthermore, treating cells with nocodazole, a microtubule-disrupting agent, resulted in an increase in the number of small aggregates particles. Indeed, perturbation of microtubule system due to inhibition of microtubule assembly or due to deletion of genes involved in microtubule biogenesis stimulates alphasyn aggregation and toxicity [122]. Also Webb and coworkers found that microtubule disruption with nocodazole inhibits autophagosome-lysosome fusion, what can decrease the degradation of alpha-syn oligomers [123]. Our group demonstrated that taxol, a microtubule stabilizer, was able to reduce alpha-syn oligomers accumulation in PD cybrids [98]. Intriguingly, the process of alpha-syn fibril formation was shown to be stimulated by tubulin and two other microtubule-associated proteins [124-126]. This means that when microtubule network is disrupted, the amount of free tubulin increases triggering alpha-syn fibrillization. Indeed alpha-tubulin directly interacts with alpha-syn [127]. On the other hand, Alim and collaborators found that alphasyn is a functional microtubule-associated protein, and mutant forms of alpha-syn lose this potential [97]. Alpha-syn overexpression induces not only microtubule disruption but also impairs microtubule-dependent trafficking and induces neuritic degeneration in SH-SY5Y cells [128]. Moreover, Saha and colleagues found that the movement of alphasyn mutant forms associated with PD through axons of cultured neurons has reduced transport rates. In addition, phosphorylation of alpha-syn in serine-129 also reduces its axonal transport [129].

Mitochondria use cytoskeletal proteins as tracks for their directional movement. Interaction of mitochondria with microtubules and their movement along microtubule tracks depends on MAPs [130]. The cytoskeletal system regulates not only mitochondrial movement but also their morphology and function. Therefore, damage to microtubules interferes with mitochondria movement through axons. On the other hand, mitochondria damage perturbs transport of mitochondria through axons, increasing their retrograde movement. These changes in mitochondria dynamics lead to a decrease of mitochondria numbers in axons and mitochondria accumulation in cell bodies [131, 132]. Studies from 2002 revealed that depletion of mitochondria numbers and function in axons occurs in neurodegenerative disorders [133, 134]. Since mitochondria are ATP suppliers and microtubules need ATP to accomplish their function, damage to mitochondria will have a profound effect on axonal transport and as a consequence axonal maintenance and function [135]. Normal mitochondria are expected to generate sufficient amounts of ATP but also to divide [136]. Indeed, mitochondrial biogenesis occurs by fission of pre-existing mitochondria. Fission allows the dilution of damaged macromolecules and also prevents excessive mitochondria enlargement. In fact, enlarged mitochondria are less likely to be degraded by mitophagy, which potentiates their progressive failure [137]. Initial enlargement may occur because of oxidative damage to proteins responsible for mitochondrial fission or mutations in the corresponding nuclear genes. Moreover, mitochondrial turnover may also decrease due to decreased lysosomal capacity associated with lipofuscin overload. It is also called "ageing pigment" and has been considered a reliable biomarker for the age of neurons. Lipofuscin is an intralysosomal, polymeric substance, primarily composed of cross-linked protein residues and formed due to iron-catalyzed oxidative processes. Because it is undegradable and cannot be removed via exocytosis, lipofuscin accumulation is inevitable during ageing [138, 139]. The accumulation of lipofuscin within postmitotic cells is a recognized hallmark of ageing occurring with a rate related to longevity.

An increasing body of data emphasizes the crucial role of mitochondrial dynamics in mitochondria function. Mitochondria are not a static and autonomous organelle but, instead, a highly dynamic one. This organelle undergoes continual cycles of fusion (the combination of two mitochondria into a single organelle) and fission (the separation of long, tubular mitochondrion into two or more smaller parts) [140, 141]. These dynamic processes regulate mitochondrial function by enabling mitochondrial recruitment to critical subcellular compartments, content exchange between mitochondria, mitochondrial shape control, mitochondrial communication with the cytosol, and mitochondrial quality control. In fact, this highly dynamic balance between mitochondrial fission and fusion controls mitochondrial morphology, length, size, and number and also regulates mitochondrial function and distribution. Increasing evidence suggests that abnormal mitochondrial dynamics is involved in mitochondrial dysfunction which may mediate neuronal death in PD models. Interestingly, $\mathrm{MPP}^{+}$and rotenone were shown to induce mitochondrial fragmentation dependent on the fission protein GTPase 
Dynamin-related protein 1 (Drp1) [142-144]. Similarly, 6OHDA-induced mitochondrial fragmentation in SH-SY5Y cells suggests that excessive mitochondrial fission might be mediating neurotoxicity induced by complex I inhibition [145]. In human fibroblasts, acute exposure to high-dose rotenone resulted in decreased mitochondrial membrane potential that caused mitochondrial fragmented morphology [146]. Also chronic exposure to rotenone was reported to reduce mitochondrial movement in differentiated dopaminergic SH-SY5Y cells [147]. These results suggest that PD toxins hamper fission/fusion machinery. Work obtained with two PD-related genes also highlighted microtubules involvement in PD as well as mitochondria dynamics impairment. For instance, parkin was shown to strongly bind to microtubules and to ubiquinate tubulin [120]. In addition, PINK-1 was found to have a role in the trafficking of mitochondria along microtubules suggesting that loss of PINK-1 function besides altering mitochondrial morphology and dynamics can also alter microtubule function [148]. It was also suggested that the PINK-1/Parkin pathway promotes mitochondrial fission and/or inhibits fusion by negatively regulating fusion proteins function, such as Mitofusin-1 and -2 (Mfn1 and Mfn2) and Optic atrophy 1 (Opa1), and/or positively regulating Drp1 [149]. Moreover, the loss of mitochondrial integrity in PINK-1 and parkin mutants can be due to reduced mitochondrial fission [150]. In Drosophila, PINK-1 and parkin mutant phenotypes were markedly suppressed by overexpression of Drp1 or downregulation of Opal indicating that the PINK-1/Parkin pathway regulates mitochondrial remodeling process by promoting mitochondrial fission [151]. Additionally, PINK1 deficiency is also linked to mitochondrial pathology in human cells and Drosophila, which can be rescued by Exner et al. [152]. Lutz and colleagues demonstrated that an acute downregulation of parkin in human SH-SY5Y cells severely affects mitochondrial morphology and function, a phenotype comparable with that induced by PINK-1 deficiency. Furthermore, they showed that loss of parkin or PINK-1 function increases Drp1-dependent mitochondrial fragmentation [153]. Narendra and colleagues demonstrated that dysfunctional mitochondria, with a low membrane potential, recruit parkin to the mitochondria and induce the mitochondria to undergo fusion and mitophagy [154]. Furthermore, the loss of PINK-1 function elicited oxidative stress and mitochondrial turnover that was coordinated by the autophagic and fission/fusion machineries [155, 156].

Overall, mitochondrial-mediated microtubule disruption leads to a rapid accumulation of protein aggregates and/or damaged organelles such as mitochondria contributing to neurodegeneration as seen in PD.

\section{Protein Aggregation: Alpha-Synuclein Oligomerization}

When misfolded proteins cannot be refolded or degraded (by the proteasome or by the lysosome), the cell activates an alternative way of defence, sequestering abnormal and/or toxic proteins into aggregates. There is convincing data pointing to protein aggregation role in both familial and sporadic PD pathogenic process. Indeed, the presence of spherical protein inclusions is found in the cytoplasm of surviving nigral neurons, named LBs. It is thought that fibrillar alpha-syn is the building block of LBs. Indeed, alphasyn is also the most sensitive marker for LBs, implying that it is necessary for LBs formation [157]. Nevertheless, LBs contain many proteins other than alpha-syn, including neurofilaments and other cytoskeletal proteins, suggesting that they might be important in aggresome formation. Alpha-syn is a small, highly charged 140-amino acid residue protein predominantly expressed in CNS, whose function is still poorly understood. However, several functions have been pointed out. It is thought that alpha-syn plays a role in the regulation of dopamine biosynthesis via activation of protein phosphatase $2 \mathrm{~A}$ that reduces tyrosine hydroxylase phosphorylation, the rate-limiting enzyme in dopamine production $[158,159]$, and reducing the amount of available active mitogen-activated protein kinases [160] and phospholipase D [161]. Furthermore, several studies suggest that alpha-syn is involved in modulating synaptic transmission, the density of synaptic vesicles, and neuronal plasticity [162165]. In addition, alpha-syn can act as molecular chaperone preventing aggregation of other proteins in vitro. In fact, alpha-syn can activate Hsp70, and more interestingly its structure is very similar to heat shock proteins [166, 167]. It also provides a supportive role in the folding/refolding of SNARE proteins critical for neurotransmitter release, vesicle recycling, and synaptic integrity [168]. Interestingly, alphasyn knockout mouse showed no signs of neurodegeneration suggesting that alpha-syn is not required for neuronal development $[165,169]$. SNCA gene mutations are very rare (three missense point mutations A30P, A53T, and E46K) however, they have helped to elucidate molecular mechanism of intracellular accumulation of alpha-syn. Transgenic mice expressing human wild-type alpha-syn gene develop several of clinical and pathological features of PD, such as accumulation of LBs, the loss of dopaminergic terminals in the basal ganglia, and associated motor impairments [170]. Overexpression of alpha-syn in substantia nigra results in loss of dopaminergic neurons, phosphorylation of alphasyn at Ser129, and activation of caspase-9 [171]. Moreover, A53T and A30P alpha-syn transgenic mice develop neuronal mitochondrial degeneration and cell death [172]. Interestingly, A30P and A53T mutant alpha-syn are known to selfassociate more rapidly than the wild-type forms facilitating aggregation into fibrils [173-176]. However, transgenic mice with A30P alpha-syn mutation do not exhibit alpha-syn inclusions [177]. In contrast, A53T alpha-syn transgenic mice develop neuronal synucleinopathy [178].

Alpha-syn can interact with many proteins, like calpain 1 that can cleave alpha-syn in the C-terminal region further enhancing its fibrillization process [179]. Likewise, alphatubulin induces alpha-syn fibrillization in yeast, rat brain, and human brain $[122,125]$. Moreover, work from our lab demonstrated that in PD cybrids with a complex I defect and ATP depletion both calpain 1 over-activation and free alpha-tubulin increase trigger alpha-syn oligomerization [98, 103]. Numerous studies now support the hypothesis that 
alpha-syn oligomerization is the key step driving neuronal damage in PD. Indeed, the idea that oligomers, rather than the fibrils, are the pathogenic aggregate species that are responsible for neuronal cell death in $\mathrm{PD}$ is emerging. In fact, based on several observations, it has been suggested that LB formation does not cause but, instead, protects against neurodegeneration $[180,181]$. Interestingly, neuropathological analysis of $\mathrm{PD}$ patients' brains has shown that neurons containing LBs seem healthier than neighbouring neurons $[182,183]$. Although the mechanism underlying the cytotoxicity of the oligomers is not clear [184, 185], earlier studies showed that alpha-syn protofibrils disrupt synthetic vesicles in vitro $[186,187]$ causing imbalance of cellular ions and, thus, cell death. Several alpha-syn posttranslational modifications lead to the formation of stable oligomers. These include nitration, oxidation, phosphorylation, and interaction with iron. Oxidative modification of alpha-syn via dopamine adducts may facilitate aggregation [175]. Similarly, recent data demonstrated that stable overexpression of alpha-syn in SH-SY5Y cells or exposure of cells to dopamine facilitated alpha-syn oligomerization [188]. Dopamine was shown to modulate differently the stability of protofibrils and fibrils composed of wild-type or mutant forms of alphasyn [189]. Wakamatsu and coworkers showed that truncated human alpha-syn is deleterious to the development and survival of nigral dopaminergic neurons [190]. Likewise, a work from 2007 demonstrated that aggregated alpha-syn mediates dopaminergic neurons toxicity in vivo [191].

Other mechanisms showed that alpha-syn aggregation might be closely related to oxidative reactions which may play a critical role in PD neurodegeneration [192]. For instance, abnormalities in copper and $\mathrm{H}_{2} \mathrm{O}_{2}$ homeostasis were shown to play critical roles in the metal-catalyzed oxidative oligomerization of alpha-syn [193]. Additionally, by using antibodies to specific nitrated tyrosine residues in alpha-syn, extensive and widespread accumulation of nitrated alpha-syn protein inclusions was demonstrated in protein inclusions of PD brains [72]. Subsequently, it was found that in HEK 293 cells stably transfected with wildtype and mutant alpha-syn, nitrative and oxidative insults induced the formation of alpha-syn aggregates [194]. Our results in $\mathrm{PD}$ cybrids indicate that mitochondrial-driven ROS production induces alpha-syn oxidation and oligomerization. Alpha-syn aggregation was significantly decreased upon antioxidant treatment (CoenzymeQ or GSH) [30].

Other important covalent promoter of aggregation is phosphorylation. Alpha-syn carries a number of potential sites for phosphorylation. Indeed, Ser129 phosphorylation of alpha-syn strongly modulates interactions between alphasyn and synphilin-1 and the formation of inclusions. The levels of soluble alpha-syn oligomeric species are increased by phosphorylation at Ser129 [195]. It was shown that alphasyn is extensively phosphorylated in aggregates from synucleinopathies patients [196]. In addition, polyunsaturated fatty acids were reported to promote oligomerization, suggesting that alpha-syn may aggregate via interaction with cell membranes [197]. One proposed mechanism for oligomers toxicity, as previously mentioned, is the formation of pores by ring-like intermediates. Moreover, iron was shown to specifically induce alpha-syn aggregation suggesting its role in aggregate formation [198].

Evidences suggest that mitochondrial dysfunction could induce alpha-syn misfolding. In fact, treatment with rotenone resulted in an increase of detergent-resistant alphasyn aggregates in COS-7 cells expressing wild-type alpha-syn [199]. Moreover, mutant and wild-type alpha-syn interacts with mitochondrial cytochrome c oxidase, a key enzyme of the mitochondrial respiratory system [200]. Li and coworkers demonstrated that a portion of alpha-syn is present in the membrane of mitochondria in normal dopaminergic neurons [201]. Under overexpression conditions, alpha-syn may translocate to the mitochondria and cause enhanced toxicity in response to subtoxic concentrations of mitochondrial toxins [202]. Using SHSY cells overexpressing alphasyn A53T mutant or wild-type, as well as isolated rat brain mitochondria, it was shown that alpha-syn localizes at the mitochondrial membrane causing oxidative stress [76]. More recently, Devi and colleagues showed that mitochondria of PD-vulnerable substantia nigra and striatum had significant accumulation of alpha-syn and decreased complex I activity [203]. Another interesting study demonstrated that during the ageing process in yeast, functional mitochondria are required for alpha-syn toxicity [204]. Furthermore, our work provided data showing that PD cybrids harbouring inherent mitochondrial impairment developed alpha-syn oligomers accumulation. Alpha-syn oligomerization in our studies was triggered by several different pathways all dependent on mitochondria malfunction (reviewed by [205]).

Although more studies need to be performed in order to elucidate alpha-syn function, it is quite undeniable that its oligomerization seems to be the key step that drives both pathology and cellular damage in PD.

\section{Intracellular Mechanisms of Degradation}

5.1. Calpain-Mediated Proteolysis. Sustained mitochondrial dysfunction in $\mathrm{PD}$ can release calcium, contributing to aberrant calcium homeostasis in the cytosol leading to activation of calpains. Indeed, mtDNA-depleted cells exhibit an increase in calpain activation [206]. Calpains are calciumactivated neuronal proteases that belong to a highly conserved family of cysteine proteases, thus, they are widely expressed in the CNS and are preferentially involved in the degradation of short-lived proteins [207]. Its structure consists of a cysteine-proteinase domain combined with a calmodulin-like $\mathrm{Ca}^{2+}$-binding domain. In fact, the activities of the representative classical, ubiquitous mammalian calpains, $\mu$-calpain (calpain 1), and m-calpain (calpain 2) are regulated by $\mathrm{Ca}^{2+}$ concentration. They exist as a proenzyme heterodimer $(80 \mathrm{kDa}$ and $29 \mathrm{kDa})$ in resting cells but are activated by calcium through autolytic processing (to produce a heterodimer of $78 \mathrm{kDa}$ and $18 \mathrm{kDa}$ ). Furthermore, in vitro studies showed that calpain 1 and 2 differ in the calcium concentration required to become activated; calpain 1 requires a calcium concentration in the $\mu$ molar range, and calpain 2 requires mmolar range [208]. It is widely known that calpastatin, a ubiquitously expressed $110 \mathrm{kDa}$ protein, 
is the sole endogenous inhibitor of calpains [209, 210]. Overall, calpains are intracellular nonlysosomal calciumregulated cysteine proteases that mediate regulatory cleavages of specific substrates and are involved in a number of processes during differentiation, life, and death of the cell. These proteases cleave diverse proteins species, including receptors, ion channels, cytoskeletal components, proteases, oncogenic proteins, and cell signalling proteins. Although calpain activation was initially implicated in the necrotic process, several studies have indicated that these proteases play a prominent role in apoptotic processes. In fact, calpains are able to be activated via caspase-mediated cleavage of calpastatin during initiation of apoptotic execution [211]. Active caspase- 3 can cleave calpastatin, thereby promoting uncontrolled calpain activation. Although calpains may enhance caspase activity, they can also function to block the activation of caspases. For example, calpains can cleave caspase-9 rendering it incapable of activating caspase-3 and preventing the subsequent apoptotic cascade [212]. Moreover, procaspase- 3 is a calpain substrate. In PC12 cells, $\mathrm{MPP}^{+}$induced calpain activation and AIF release which was prevented by calpain inhibitors [213].

Cdk 5 belongs to a group of serine/threonine kinases best characterized for their role in cell cycle progression. This kinase was shown to have a role in the pathogenesis of PD. Cdk5 has been colocalized with LBs in PD patients' brains. Conversion of the cdk5 activator p35 to the more stable p 25 form may lead to increased cdk5 activity. Consistent with this possibility, an increase in p25 levels was shown after MPTP treatment. Several reports suggest that the p35-top25 conversion is mediated through calpain activation [214216]. Increased expression of calpain in the mesencephalon of PD patients and primate PD models has been demonstrated, suggesting a calpain involvement in PD pathogenesis [217]. Additionally, enhanced calpain expression and activity is observed in the substantia nigra and locus coeruleus of PD patients. Increased calpain expression and cell death in spinal cord in C57BL/6N mice were also reported following MPTP treatment [218]. The presence of calpains in morphologically abnormal dopaminergic fibers as well as in LBs further supports calpains involvement in PD. Most interestingly, inhibition of calpain blocks neuronal degeneration and restores behavioural function in experimental models of $\mathrm{PD}$ [219]. Likewise, the inhibition of mitochondrial complex I by $\mathrm{MPP}^{+}$and rotenone activated calpain and seems to constitute an early event in the neurodegenerative process prior to caspase-3 activation [220, 221]. Moreover, rotenoneinduced degeneration of spinal cord motor-neuron in male Lewis rats progressed with upregulation of calpain and caspase-3 [222].

It is now well accepted that alpha-syn oligomerization is pivotal in progression of PD pathology and cellular damage. Subsequently, it has been described in other diseases that involve protein aggregation, the protective effect of calpain inhibition. Haacke and coworkers showed that coexpression of the highly specific cellular calpain inhibitor calpastatin abrogated fragmentation and the formation of inclusions in cells expressing pathological ataxin-3 suggesting a critical role of calpain in the pathogenesis of Spinocerebellar ataxia type 3 [223]. Moreover, Goñi-Oliver and colleagues provided data that established the first direct evidence that calpain promotes GSK-3 truncation in a way that has implications in signal transduction, and probably in pathological disorders such as $\mathrm{AD}$ [224]. In 2003, it was shown that parkin accelerates the degradation of alpha-syn via the activation of calpain leading to the prevention of alpha-syn-induced cell death [225]. Also in 2003, it was demonstrated that alpha-syn was a substrate of calpain 1 [179]. Latterly, the same group showed data revealing that calpain-mediated cleavage near and within the middle region of soluble alpha-syn with/without tyrosine nitration and oxidation generates fragments that are unable to self-fibrillized [226]. As opposed, Dufty and colleagues in 2007 showed that cleavage of alpha-syn by calpain occurs in PD brain and calpain-cleaved fragments of alphasyn colocalized with activated calpain [227]. These results suggest that calpain may link alpha-syn to its disease-linked oligomerization, aggregation, and subsequent formation of LBs. Our group showed that PD cybrids have increased cytosolic calcium levels correlated with an increase in calpain activation and expression which subsequently potentiates the formation of toxic alpha-syn oligomers. In addition, our results showed that calpains inhibition decreased the toxic alpha-syn oligomers and increased the nontoxic insoluble alpha-syn aggregates, preventing caspase-3 activation [103].

Demarchi and collaborators showed that calpain modulates macroautophagy in mammalian cells [228]. Indeed, in calpain-deficient cells, autophagy is impaired, thus contributing to the apoptotic switch. Recent data showed that in $\mathrm{AD}$ the lysosomal autophagic system may not degrade tau in the normal adult rat brain. However, inhibition of autophagy may induce tau proteolysis through calpain activation [229]. So far, no data was shown confirming the correlation between autophagy and calpains in PD.

Overall, a role for calpains-mediated proteolysis is strongly postulated in the pathogenesis of PD. More studies need to be performed to address if calpains inhibition offer a potential therapeutic target in the neurodegenerative process of PD.

5.2. Autophagy: A Quality Control System. Age causes a progressive accumulation of wornout organelles and subcellular structures that reduces the cellular and molecular efficiency of various biological processes that are required for maintaining homeostasis and survival. This accumulation of extracellular/intracellular damaged proteins has been frequently used as a biomarker of ageing [230]. Moreover, it seems to reflect an unbalance between the capability/activity of the quality control systems and the amount of altered proteins in the cells. Autophagy is ubiquitous in eukaryotic cells and is the major mechanism involved in the clearance of oxidatively or otherwise damaged/worn-out macromolecules and organelles, controlling thus cell death. Autophagy is a process traditionally regarded as a cellular response to stress typically related to nutrient deprivation, toxin exposure, infection, or oxidative stress. In contrast to the ubiquitin-proteasome pathway which degrades mostly short-lived proteins, autophagy is primarily involved in breaking down proteins with long half-lives and damaged 
organelles [231]. Moreover, is a highly organized and probably quite specific intralysosomal degradation pathway regulated by a large family of genes, the ATG family $[232,233]$. Over 30 atg genes have been identified in yeast and at least 11 have orthologs in humans. For instance, atg6 is also known as beclin and atg8 is commonly called LC3 in mammals $[234,235]$. There are three main types of autophagy in mammalian cells: macroautophagy, microautophagy, and chaperone-mediated autophagy (CMA) [236]. The differences among the various autophagic mechanisms depend of the type of cargo, route, and mechanism for its delivery to lysosomes. Macroautophagy involves any type of cellular material, including large organelles, such as mitochondria, being sequestered within a double-membrane-bounded vacuole called autophagosome. Autophagosomes receive acid hydrolases by fusion with late endosomes or lysosomes. Subsequently, the degradation of its content progresses and matures to a secondary lysosome or residual body depending on whether degradation is complete or partial, respectively [237-239]. Microautophagy involves macromolecules and small organelles that enter lysosomes through invagination of its membrane [240, 241]. CMA is a mechanism for selective digestion of a particular group of soluble cytosolic proteins with a KFERQ motif [233, 242]. Once this sequence is recognized, these proteins are directly translocated to the lysosomal membrane.

Alterations in the autophagic machinery have been implicated in the pathogenesis of PD. Indeed, an increased number of autophagic vacuoles and related structures of autophagy have been found in PD patients [243]. In addition, autophagic vacuoles are also described within mesencephalic dopaminergic neurons in several experimental models of PD [244, 245]. LC3-II and Beclin-1 expressions were significantly increased in brains from humans with Dementia with LBs and in transgenic mice overexpressing A53T alpha-syn, as compared with respective controls [246]. However, the lysosome-associated membrane protein 1 (LAMP1), cathepsin D (CatD), and Heat Shock Protein 73 (HSP73) immunoreactivity were significantly decreased within PD nigral neurons when compared to age-matched controls [247]. There is controversy over whether this increase in autophagic markers is protective or instead causes neuronal death. It has been suggested that this increase is responsible for neuronal death. However, enhanced degradation of deleterious aggregates or disrupted organelles can be protective [248].

Autophagy is indeed an important process in a variety of human diseases caused by toxic, aggregate-prone, intracytosolic proteins which became inaccessible to the proteasome when they form oligomers $[249,250]$. Depending on its conformational state and cellular conditions, alpha-syn can be degraded by autophagy [251]. CMA and macroautophagy were shown to be important pathways for wild-type alphasyn degradation in neurons [252]. Being a soluble protein, alpha-syn can be degraded by CMA because it contains the CMA recognition targeting motif [253]. None of the 3 mutations in familial forms of PD affect the CMA targeting motif. Nevertheless, the wild-type protein, contrary to the mutant forms, is readily translocated into the lysosomal lumen whereas the mutant forms remain bound to the complex not only blocking its degradation but also the degradation of other substrates. Moreover, posttranslational modifications of alpha-syn that promote its oligomerization have a similar effect, suggesting that alpha-syn oligomers may block lysosomal translocation and CMA [248]. For example, in mouse ventral medial neuron cultures, SH-SY5Y cells, and isolated mouse lysosomes, dopamine-modified alpha-syn is not only poorly degraded by CMA but also blocks degradation of other substrates by this pathway [254]. While the narrow proteasome barrel excludes the entry of oligomers/aggregates of alpha-syn, such substrates can be degraded efficiently by macroautophagy. The ability of alpha-syn to inhibit proteasome activity is related to its propensity to assemble into filaments [255]. Indeed, fibrillar forms of the protein usually get jammed inside proteasome blocking its activity [256]. Interestingly, disruption of autophagy by RNA interference significantly increased alpha-syn oligomer accumulation in vitro, confirming the significance of macroautophagy in alpha-syn clearance. In addition, rotenone-induced alphasyn aggregates were cleared following rapamycin stimulation of autophagy [246]. Rapamycin inhibits the mammalian target of rapamycin (mTOR), a negative regulator of autophagy [257]. Rapamycin has been shown to degrade all forms of alpha-syn in a stable inducible PC12 cell model [251]. These findings support the concept that neuronal autophagy is essential for protein homeostasis as well as for the reduction of the potentially pathogenic alpha-syn oligomers. Coexpression of Beclin-1, a regulator of the autophagic pathway, was found to activate autophagy, reduce accumulation of alpha-syn, and ameliorate associated neuritic alterations in a neuronal cell line that overexpressed alphasyn. This neuronal cell line showed lysosomal accumulation and alterations in autophagy [258].

Ageing seems to affect mitochondria particularly. Mitochondria undergo the most dramatic age-related changes, such as structural deterioration like swelling and loss of cristae, sometimes complete destruction of the inner membrane, decreased respiration, and low ATP production [137]. Often they are extremely enlarged and are called "giant" mitochondria $[259,260]$. Nonfunctional mitochondria are important sources of ROS which contribute to the accumulation of damaged and nonfunctional components in the cells which is characteristic of ageing. In addition, because of mitochondrial ROS generation, protein damage occurs and mtDNA mutations accumulate at an accelerating rate. Subsequently, this leads to the synthesis of abnormal mitochondrial proteins exacerbating mitochondrial dysfunction.

During recent years, accumulating evidence has been gathered showing that mitochondria also may be subject to selective degradation through mitophagy. Mitophagy is important to the elimination of dysfunctional mitochondria and mutated mtDNA since DNA repair in mitochondria is much less robust than in the nucleus [261]. There are many reports showing mitochondria within autophagosomes [262-264]. It was then proposed that damaged mitochondria are captured and digested by the lysosome. 


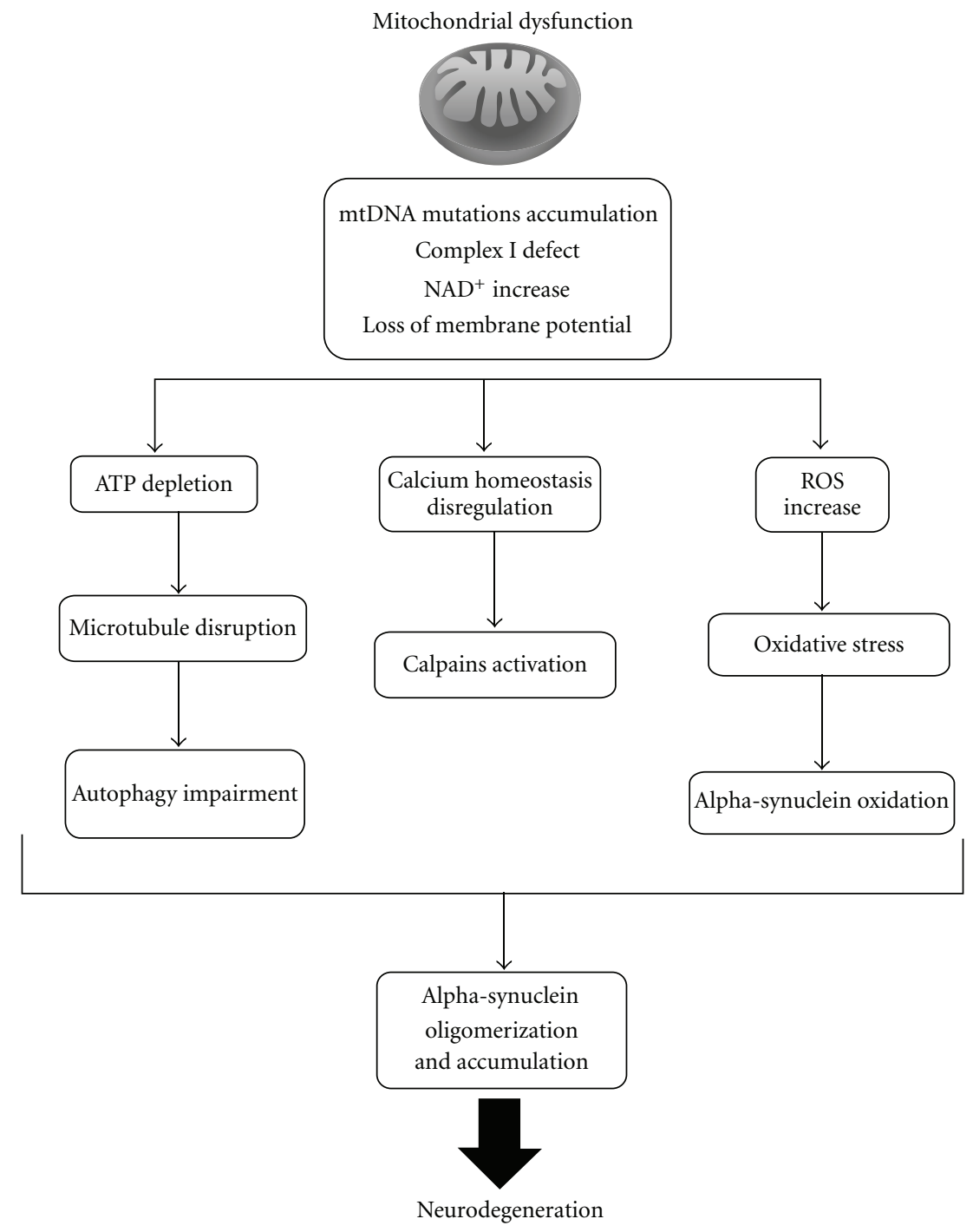

FIGURE 1: The mitochondrial cascade hypothesis for PD states that the inherited electron transport chain gene combinations determine basal ETC efficiency and ROS production. This defines the rate at which acquired mtDNA alterations occur determining when mitochondrial impairment reaches a threshold that activates the pathologic characteristics of PD. Mitochondrial impairment in PD is characterized by a complex I defect, which leads to ATP depletion and $\mathrm{NAD}^{+} / \mathrm{NADH}$ ratio imbalance promoting microtubule disruption. Moreover, mitochondrial membrane potential is lost and calcium homeostasis is deregulated, which leads to calpains activation. In addition, the levels of mitochondrial ROS are significantly increased triggering oxidative stress. These all prompt alpha-syn oligomerization either by interaction with free tubulin, calpains or by oxidation. The end result is alpha-syn oligomerization and accumulation of alpha-syn oligomers as well as of disrupted organelles culminating in neurodegeneration.

The evidence for mitophagy comes from a work in yeast that identifies a specific protein in the mitochondrial outer membrane Uth1p, whose presence is necessary for mitochondrial macroautophagy. Degradation of mitochondrial proteins did not occur in mutant strains carrying null mutations of Uth1p [265]. Additionally, autophagic sequestration of mitochondria is further supported by the observation that protein markers of mtDNA are lost together with protein markers of mitochondrial inner membrane such as cytochrome oxidase subunit IV and subunit I. Parkin and PINK-1 PD-related proteins were recently associated to mitophagy. Chu and coworkers showed that $\mathrm{MPP}^{+}$induced autophagy and mitochondrial degradation that was inhibited by siRNA knockdown of autophagy proteins Atg5, Atg7, and Atg8 [266]. Moreover, it was shown that Parkin promotes autophagy of damaged mitochondria and further supports that PD pathogenesis implicates a failure in the elimination of dysfunctional mitochondria [154]. Furthermore, stable knockdown of pink-1 induced oxidative stress and mitochondrial fragmentation in SH-SY5Y cells through autophagic and fission/fusion machineries [156]. A report from 2010 demonstrated a new interaction between PINK1 and Beclin1, a key proautophagic protein. PINK-1 significantly enhanced basal and starvation-induced autophagy, 
which was reduced by knocking down beclin 1 expression [267]. Another report provided data linking PINK-1 and parkin to the selective autophagy of mitochondria [268].

In $\mathrm{PD}$, autophagy is of extreme importance once it allows cells to rid themselves of damaged and superfluous mitochondria, as well as other organelles and most interestingly of protein aggregates accumulation.

\section{Concluding Remarks}

PD affects $1 \%$ of the population at age of 65 and up to $5 \%$ of the population by age 85 [269] and is the second most common neurodegenerative disorder after AD. Efforts have been made in order to elucidate PD trigger mechanisms within the cell and further consequences. Compelling data suggests that mtDNA alterations may lead to a massive mitochondrial impairment and thus triggering the death of dopaminergic neurons. When mitochondrial dysfunction reaches a critical threshold inside the cell it rouses ATP depletion, oxidative stress, and calcium homeostasis deregulation that in turn induces microtubule disruption, alphasyn oxidation, and calpains activation. In addition, the fusion and fission machinery is impaired as well as autophagy leading to the accumulation of alpha-syn oligomers and disrupted organelles (Figure 1). This accumulation creates a positive feedback loop causing the pathology and ultimately the death of dopaminergic neurons. Further studies need to be performed to understand how and when mitochondrial dysfunction starts and why it affects a specific group of neurons. The therapeutic challenge might start acting at an mtDNA level or at a microtubule level improving the degradation of alpha-syn oligomers and disrupted organelles.

\section{Abbreviations}

$\begin{array}{ll}\text { PD: } & \text { Parkinson's disease } \\ \text { alpha-syn: } & \text { Alpha-synuclein } \\ \text { LBs: } & \text { Lewy Bodies } \\ \text { MPTP: } & \begin{array}{l}\text { 1-methyl-4-phenyl-1,2,3,4- } \\ \text { tetrahydropyridine }\end{array} \\ \text { mtDNA: } & \text { Mitochondrial DNA } \\ \text { OXPHOS: } & \text { Oxidative phosphorylation } \\ \text { ROS: } & \text { Reactive oxygen species } \\ \text { MPP }{ }^{+}: & \text {1-methyl-4-phenylpyridinium } \\ \text { AD: } & \text { Alzheimer's disease } \\ \text { 6-OHDA: } & \text { 6-hydroxydopamine } \\ \text { POLG1: } & \text { mtDNA polymerase gamma 1 } \\ \text { NAD }: & \beta \text {-Nicotinamide adenine dinucleotide } \\ \text { NADH: } & \text { Reduced } \beta \text {-NAD } \\ \text { SIRTs: } & \text { Sirtuins } \\ \text { PGC1 } \alpha: & \text { Peroxisome proliferators activated } \\ & \text { receptor gamma coactivator-1 alpha } \\ \text { CMA: } & \text { Chaperone-mediated autophagy } \\ \text { CNS: } & \text { Central Nervous System } \\ \text { Mfn1 and Mfn2: } & \text { Mitofusin-1 and -2 } \\ \text { Opa1: } & \text { Optic atrophy 1 } \\ \text { Drp1: } & \text { GTPase Dynamin-related protein 1 } \\ & \end{array}$

LRRK2: Leucine-rich repeat kinase 2

NAM: Nicotinamide

CNS: Central Nervous System

BDNF: Brain-derived neurotrophic factor

GDNF: Glial cell line-derived neurotrophic factor.

\section{Acknowledgments}

Work in our laboratory is supported by funds from PTDC/SAU-NEU/102710/2008. A. R. Esteves and D. M. Arduíno are also supported by $\mathrm{Ph}$. D. Fellowships (nos. SFRH/BD/32470/2006 and SFRHD/BD/38743/2007, resp.) from Foundation for Science and Technology (FCT-MCTES, Portugal).

\section{References}

[1] M. H. Polymeropoulos, C. Lavedan, E. Leroy et al., "Mutation in the $\alpha$-synuclein gene identified in families with Parkinson's disease," Science, vol. 276, no. 5321, pp. 2045-2047, 1997.

[2] R. Krüger, W. Kuhn, T. Müller et al., "Ala30Pro mutation in the gene encoding $\alpha$-synuclein in Parkinson's disease," Nature Genetics, vol. 18, no. 2, pp. 106-108, 1998.

[3] M. C. Chartier-Harlin, J. Kachergus, C. Roumier et al., “ $\alpha$ synuclein locus duplication as a cause of familial Parkinson's disease," Lancet, vol. 364, no. 9440, pp. 1167-1169, 2004.

[4] P. Ibáñez, A.-M. Bonnet, B. Débarges et al., "Causal relation between $\alpha$-synuclein gene duplication and familial Parkinson's disease," Lancet, vol. 364, no. 9440, pp. 1169-1171, 2004.

[5] J. Hardy, P. Lewis, T. Revesz, A. Lees, and C. Paisan-Ruiz, "The genetics of Parkinson's syndromes: a critical review," Current Opinion in Genetics and Development, vol. 19, no. 3, pp. 254-265, 2009.

[6] E. M. Valente, P. M. Abou-Sleiman, V. Caputo et al., "Hereditary early-onset Parkinson's disease caused by mutations in PINK1," Science, vol. 304, no. 5674, pp. 1158-1160, 2004.

[7] V. Bonifati, P. Rizzu, M. J. Van Baren et al., "Mutations in the DJ-1 gene associated with autosomal recessive early-onset parkinsonism," Science, vol. 299, no. 5604, pp. 256-259, 2003.

[8] T. Kitada, S. Asakawa, N. Hattori et al., "Mutations in the parkin gene cause autosomal recessive juvenile parkinsonism," Nature, vol. 392, no. 6676, pp. 605-608, 1998.

[9] V. Bogaerts, K. Nuytemans, J. Reumers et al., "Genetic variability in the mitochondrial serine protease HTRA2 contributes to risk for Parkinson disease," Human Mutation, vol. 29, no. 6, pp. 832-840, 2008.

[10] L. M. Martins, A. Morrison, K. Klupsch et al., "Neuroprotective role of the reaper-related serine protease HtrA2/Omi revealed by targeted deletion in mice," Molecular and Cellular Biology, vol. 24, no. 22, pp. 9848-9862, 2004.

[11] J. M. Jones, P. Datta, S. M. Srinivasula et al., "Loss of Omi mitochondrial protease activity causes the neuromuscular disorder of mnd2 mutant mice," Nature, vol. 425, no. 6959, pp. 721-727, 2003.

[12] S. Biskup, D. J. Moore, F. Celsi et al., "Localization of LRRK2 to membranous and vesicular structures in mammalian brain," Annals of Neurology, vol. 60, no. 5, pp. 557-569, 2006. 
[13] S. Saha, M. D. Guillily, A. Ferree et al., "LRRK2 modulates vulnerability to mitochondrial dysfunction in Caenorhabditis elegans," Journal of Neuroscience, vol. 29, no. 29, pp. 9210 9218, 2009.

[14] L. Tretter, I. Sipos, and V. Adam-Vizi, "Initiation of neuronal damage by complex I deficiency and oxidative stress in Parkinson's disease," Neurochemical Research, vol. 29, no. 3, pp. 569-577, 2004.

[15] J. W. Langston, P. Ballard, J. W. Tetrud, and I. Irwin, "Chronic parkinsonism in humans due to a product of meperidineanalog synthesis," Science, vol. 219, no. 4587, pp. 979-980, 1983.

[16] W. D. Parker Jr., S. J. Boyson, and J. K. Parks, "Abnormalities of the electron transport chain in idiopathic Parkinson's disease," Annals of Neurology, vol. 26, no. 6, pp. 719-723, 1989.

[17] A. H. V. Schapira, J. M. Cooper, D. Dexter, J. B. Clark, P. Jenner, and C. D. Marsden, "Mitochondrial Complex I deficiency in Parkinson's disease," Journal of Neurochemistry, vol. 54, no. 3, pp. 823-827, 1990.

[18] V. M. Mann, J. M. Cooper, D. Krige, S. E. Daniel, A. H. V. Schapira, and C. D. Marsden, "Brain, skeletal muscle and platelet homogenate mitochondrial function in Parkinson's disease," Brain, vol. 115, no. 2, pp. 333-342, 1992.

[19] Y. Mizuno, S. Ohta, M. Tanaka et al., "Deficiencies in complex I subunits of the respiratory chain in Parkinson's disease," Biochemical and Biophysical Research Communications, vol. 163, no. 3, pp. 1450-1455, 1989.

[20] P. M. Keeney, J. Xie, R. A. Capaldi, and J. P. Bennett, "Parkinson's disease brain mitochondrial complex I has oxidatively damaged subunits and is functionally impaired and misassembled," Journal of Neuroscience, vol. 26, no. 19, pp. 5256-5264, 2006.

[21] H. Yoshino, Y. Nakagawa-Hattori, T. Kondo, and Y. Mizuno, "Mitochondrial complex I and II activities of lymphocytes and platelets in Parkinson's disease," Journal of Neural Transmission, vol. 4, no. 1, pp. 27-34, 1992.

[22] D. Krige, M. T. Carroll, J. M. Cooper, C. D. Marsden, and A. H. V. Schapira, "Platelet mitochondrial function in Parkinson's disease," Annals of Neurology, vol. 32, no. 6, pp. 782-788, 1992.

[23] R. H. Haas, F. Nasirian, K. Nakano et al., "Low platelet mitochondrial complex I and complex II/III activity in early untreated Parkinson's disease," Annals of Neurology, vol. 37, no. 6, pp. 714-722, 1995.

[24] W. D. Parker Jr. and R. H. Swerdlow, "Mitochondrial dysfunction in idiopathic Parkinson disease," American Journal of Human Genetics, vol. 62, no. 4, pp. 758-762, 1998.

[25] J. M. Shoffner, R. L. Watts, J. L. Juncos, A. Torroni, and D. C. Wallace, "Mitochondrial oxidative phosphorylation defects in Parkinson's disease," Annals of Neurology, vol. 30, no. 3, pp. 332-339, 1991.

[26] C. Mytilineou, P. Werner, S. Molinari, A. Di Rocco, G. Cohen, and M. D. Yahr, "Impaired oxidative decarboxylation of pyruvate in fibroblasts from patients with Parkinson's disease," Journal of Neural Transmission, vol. 8, no. 3, pp. 223228, 1994.

[27] W. D. Parker Jr., J. K. Parks, and R. H. Swerdlow, "Complex I deficiency in Parkinson's disease frontal cortex," Brain Research, vol. 1189, no. 1, pp. 215-218, 2008.

[28] M. P. King and G. Attardi, "Human cells lacking mtDNA: repopulation with exogenous mitochondria by complementation," Science, vol. 246, no. 4929, pp. 500-503, 1989.
[29] A. R. F. Esteves, A. F. Domingues, I. L. Ferreira et al., "Mitochondrial function in Parkinson's disease cybrids containing an nt2 neuron-like nuclear background," Mitochondrion, vol. 8, no. 3, pp. 219-228, 2008.

[30] A. R. Esteves, D. M. Arduíno, R. H. Swerdlow, C. R. Oliveira, and S. M. Cardoso, "Oxidative stress involvement in $\alpha$ synuclein oligomerization in Parkinson's disease cybrids," Antioxidants and Redox Signaling, vol. 11, no. 3, pp. 439-448, 2009.

[31] M. Gu, J. M. Cooper, J. W. Taanman, and A. H. V. Schapira, "Mitochondrial DNA transmission of the mitochondrial defect in Parkinson's disease," Annals of Neurology, vol. 44, no. 2, pp. 177-186, 1998.

[32] R. H. Swerdlow, J. K. Parks, S. W. Miller et al., "Origin and functional consequences of the complex I defect in Parkinson's disease," Annals of Neurology, vol. 40, no. 4, pp. 663-671, 1996.

[33] T. P. Brown, P. C. Rumsby, A. C. Capleton, L. Rushton, and L. S. Levy, "Pesticides and Parkinson's disease-is there a link?" Environmental Health Perspectives, vol. 114, no. 2, pp. 156164, 2006.

[34] J. M. Hatcher, K. D. Pennell, and G. W. Miller, "Parkinson's disease and pesticides: a toxicological perspective," Trends in Pharmacological Sciences, vol. 29, no. 6, pp. 322-329, 2008.

[35] A. Ascherio, H. Chen, M. G. Weisskopf et al., "Pesticide exposure and risk for Parkinson's disease," Annals of Neurology, vol. 60, no. 2, pp. 197-203, 2006.

[36] R. Betarbet, T. B. Sherer, G. MacKenzie, M. Garcia-Osuna, A. V. Panov, and J. T. Greenamyre, "Chronic systemic pesticide exposure reproduces features of Parkinson's disease," Nature Neuroscience, vol. 3, no. 12, pp. 1301-1306, 2000.

[37] T. B. Sherer, J. H. Kim, R. Betarbet, and J. T. Greenamyre, "Subcutaneous rotenone exposure causes highly selective dopaminergic degeneration and $\alpha$-synuclein aggregation," Experimental Neurology, vol. 179, no. 1, pp. 9-16, 2003.

[38] S. Ramachandiran, J. M. Hansen, D. P. Jones, J. R. Richardson, and G. W. Miller, "Divergent mechanisms of paraquat, MPP, and rotenone toxicity: oxidation of thioredoxin and caspase-3 activation," Toxicological Sciences, vol. 95, no. 1, pp. 163-171, 2007.

[39] K. Ossowska, J. Wardas, M. Śmiałowska et al., "A slowly developing dysfunction of dopaminergic nigrostriatal neurons induced by long-term paraquat administration in rats: an animal model of preclinical stages of Parkinson's disease?" European Journal of Neuroscience, vol. 22, no. 6, pp. 12941304, 2005.

[40] A. B. Manning-Boğ, A. L. McCormack, M. G. Purisai, L. M. Bolin, and D. A. Di Monte, " $\alpha$-synuclein overexpression protects against paraquat-induced neurodegeneration," Journal of Neuroscience, vol. 23, no. 8, pp. 3095-3099, 2003.

[41] G. Meco, V. Bonifati, N. Vanacore, and E. Fabrizio, "Parkinsonism after chronic exposure to the fungicide maneb (manganese ethylene-bis-dithiocarbamate)," Scandinavian Journal of Work, Environment and Health, vol. 20, no. 4, pp. 301-305, 1994.

[42] G. S. Morato, T. Lemos, and R. N. Takahashi, "Acute exposure to maneb alters some behavioral functions in the mouse," Neurotoxicology and Teratology, vol. 11, no. 5, pp. 421-425, 1989.

[43] F. Cicchetti, A. L. Brownell, K. Williams, Y. I. Chen, E. Livni, and O. Isacson, "Neuroinflammation of the nigrostriatal pathway during progressive 6-OHDA dopamine degeneration in rats monitored by immunohistochemistry and PET 
imaging," European Journal of Neuroscience, vol. 15, no. 6, pp. 991-998, 2002.

[44] D. J. S. Sirinathsinghji, R. P. Heavens, S. J. Richards, I. J. M. Beresford, and M. D. Hall, "Experimental hemiparkinsonism in the rat following chronic unilateral infusion of MPP into the nigrostriatal dopamine pathway-I. Behavioural, neurochemical and histological characterization of the lesion," Neuroscience, vol. 27, no. 1, pp. 117-128, 1988.

[45] A. Bender, K. J. Krisham, and C. M. Morris, "High levels of mitochondrial DNA deletions in Substantia nigra neurons in ageing and Parkinson disease," Nature Genetics, vol. 38, no. 5, pp. 515-517, 2006.

[46] A. K. Reeve, K. J. Krishnan, J. L. Elson et al., "Nature of mitochondrial DNA deletions in Substantia nigra neurons," American Journal of Human Genetics, vol. 82, no. 1, pp. 228235, 2008.

[47] N. G. Larsson, J. Wang, H. Wilhelmsson et al., "Mitochondrial transcription factor A is necessary for mtDNA maintenance and embryogenesis in mice," Nature Genetics, vol. 18, no. 3, pp. 231-236, 1998.

[48] M. I. Ekstrand, M. Falkenberg, A. Rantanen et al., "Mitochondrial transcription factor A regulates mtDNA copy number in mammals," Human Molecular Genetics, vol. 13, no. 9, pp. 935-944, 2004.

[49] M. Falkenberg, M. Gaspari, A. Rantanen, A. Trifunovic, N. G. Larsson, and C. M. Gustafsson, "Mitochondrial transcription factors B1 and B2 activate transcription of human mtDNA," Nature Genetics, vol. 31, no. 3, pp. 289-294, 2002.

[50] M. I. Ekstrand, M. Terzioglu, D. Galter et al., "Progressive parkinsonism in mice with respiratory-chain-deficient dopamine neurons," Proceedings of the National Academy of Sciences of the United States of America, vol. 104, no. 4, pp. 1325-1330, 2007.

[51] K. Gaweda-Walerych, K. Safranow, A. Maruszak et al., "Mitochondrial transcription factor A variants and the risk of Parkinson's disease," Neuroscience Letters, vol. 469, no. 1, pp. 24-29, 2010.

[52] V. Alvarez, A. I. Corao, E. Sánchez-Ferrero et al., "Mitochondrial transcription factor A (TFAM) gene variation in Parkinson's disease," Neuroscience Letters, vol. 432, no. 1, pp. 79-82, 2008.

[53] G. Hudson and P. F. Chinnery, "Mitochondrial DNA polymerase- $\gamma$ and human disease," Human Molecular Genetics, vol. 15, no. 2, pp. R244-R252, 2006.

[54] P. T. Luoma, J. Eerola, S. Ahola et al., "Mitochondrial DNA polymerase gamma variants in idiopathic sporadic Parkinson disease," Neurology, vol. 69, no. 11, pp. 1152-1159, 2007.

[55] G. Hudson, A. M. Schaefer, R. W. Taylor et al., "Mutation of the linker region of the polymerase $\gamma$-1 (POLG1) gene associated with progressive external ophthalmoplegia and parkinsonism," Archives of Neurology, vol. 64, no. 4, pp. 553557, 2007.

[56] G. Davidzon, P. Greene, M. Mancuso et al., "Early-onset familial parkinsonism due to POLG mutations," Annals of Neurology, vol. 59, no. 5, pp. 859-862, 2006.

[57] W. S. Choi, S. E. Kruse, R. D. Palmiter, and Z. Xia, "Mitochondrial complex I inhibition is not required for dopaminergic neuron death induced by rotenone, MPP, or paraquat," Proceedings of the National Academy of Sciences of the United States of America, vol. 105, no. 39, pp. 1513615141, 2008.

[58] M. Marella, B. B. Seo, E. Nakamaru-Ogiso, J. T. Greenamyre, A. Matsuno-Yagi, and T. Yagi, "Protection by the NDI1 gene against neurodegeneration in a rotenone rat model of
Parkinson's disease," PLoS ONE, vol. 3, no. 1, article no. e1433, 2008.

[59] M. Marella, B. B. Seo, T. Yagi, and A. Matsuno-Yagi, "Parkinson's disease and mitochondrial complex I: a perspective on the Ndil therapy," Journal of Bioenergetics and Biomembranes, vol. 41, no. 6, pp. 493-497, 2009.

[60] A. Yoritaka, N. Hattori, K. Uchida, M. Tanaka, E. R. Stadtman, and Y. Mizuno, "Immunohistochemical detection of 4-hydroxynonenal protein adducts in Parkinson disease," Proceedings of the National Academy of Sciences of the United States of America, vol. 93, no. 7, pp. 2696-2701, 1996.

[61] D. T. Dexter, C. J. Carter, F. R. Wells et al., "Basal lipid peroxidation in Substantia nigra is increased in Parkinson's disease," Journal of Neurochemistry, vol. 52, no. 2, pp. 381389, 1989.

[62] J. Zhang, G. Perry, M. A. Smith et al., "Parkinson's disease is associated with oxidative damage to cytoplasmic DNA and RNA in Substantia nigra neurons," American Journal of Pathology, vol. 154, no. 5, pp. 1423-1429, 1999.

[63] Z. I. Alam, S. E. Daniel, A. J. Lees, D. C. Marsden, P. Jenner, and B. Halliwell, "A generalised increase in protein carbonyls in the brain in Parkinson's but not incidental Lewy body disease," Journal of Neurochemistry, vol. 69, no. 3, pp. 13261329, 1997.

[64] E. Floor and M. G. Wetzel, "Increased protein oxidation in human Substantia nigra pars compacta in comparison with basal ganglia and prefrontal cortex measured with an improved dinitrophenylhydrazine assay," Journal of Neurochemistry, vol. 70, no. 1, pp. 268-275, 1998.

[65] P. Jenner, "Altered mitochondrial function, iron metabolism and glutathione levels in Parkinson's disease," Acta Neurologica Scandinavica, vol. 87 , no. 146, supplement, pp. 6-13, 1993.

[66] M. Basso, S. Giraudo, D. Corpillo, B. Bergamasco, L. Lopiano, and M. Fasano, "Proteome analysis of human Substantia nigra in Parkinson's disease," Proteomics, vol. 4, no. 12, pp. 3943-3952, 2004.

[67] C. Richter, J. W. Park, and B. N. Ames, "Normal oxidative damage to mitochondrial and nuclear DNA is extensive," Proceedings of the National Academy of Sciences of the United States of America, vol. 85, no. 17, pp. 6465-6467, 1988.

[68] T. Ozawa, "Oxidative damage and fragmentation of mitochondrial DNA in cellular apoptosis," Bioscience Reports, vol. 17, no. 3, pp. 237-250, 1997.

[69] S. J. Chinta and J. K. Andersen, "Redox imbalance in Parkinson's disease," Biochimica et Biophysica Acta, vol. 1780, no. 11, pp. 1362-1367, 2008.

[70] M. Gesi, A. Santinami, R. Ruffoli, G. Conti, and F. Fornai, "Novel aspects of dopamine oxidative metabolism (confounding outcomes take place of certainties)," Pharmacology and Toxicology, vol. 89, no. 5, pp. 217-224, 2001.

[71] D. Sulzer and L. Zecca, "Intraneuronal dopamine-quinone synthesis: a review," Neurotoxicity Research, vol. 1, no. 3, pp. 181-195, 2000.

[72] B. I. Giasson, J. E. Duda, I. V. J. Murray et al., "Oxidative damage linked to neurodegeneration by selective $\alpha$-synuclein nitration in synucleinopathy lesions," Science, vol. 290, no. 5493, pp. 985-989, 2000.

[73] K. K. K. Chung, B. Thomas, X. Li et al., "S-nitrosylation of parkin regulates ubiquitination and compromises parkin's protective function," Science, vol. 304, no. 5675, pp. 13281331, 2004.

[74] D. Yao, Z. Gu, T. Nakamura et al., "Nitrosative stress linked to sporadic Parkinson's disease: S-nitrosylation of parkin 
regulates its E3 ubiquitin ligase activity," Proceedings of the National Academy of Sciences of the United States of America, vol. 101, no. 29, pp. 10810-10814, 2004.

[75] S. L. Leong, C. L. L. Pham, D. Galatis et al., "Formation of dopamine-mediated $\alpha$-synuclein-soluble oligomers requires methionine oxidation," Free Radical Biology and Medicine, vol. 46, no. 10, pp. 1328-1337, 2009.

[76] M. S. Parihar, A. Parihar, M. Fujita, M. Hashimoto, and P. Ghafourifar, "Mitochondrial association of alpha-synuclein causes oxidative stress," Cellular and Molecular Life Sciences, vol. 65, no. 7-8, pp. 1272-1284, 2008.

[77] A. Mitsumoto and Y. Nakagawa, "DJ-1 is an indicator for endogenous reactive oxygen species elicited by endotoxin," Free Radical Research, vol. 35, no. 6, pp. 885-893, 2001.

[78] T. Hayashi, C. Ishimori, K. Takahashi-Niki et al., "DJ-1 binds to mitochondrial complex I and maintains its activity," Biochemical and Biophysical Research Communications, vol. 390, no. 3, pp. 667-672, 2009.

[79] G. S. Watson and S. Craft, "The role of insulin resistance in the pathogenesis of Alzheimer's disease: implications for treatment," CNS Drugs, vol. 17, no. 1, pp. 27-45, 2003.

[80] B. A. Yankner, T. Lu, and P. Loerch, “The aging brain," Annual Review of Pathology, vol. 3, pp. 41-66, 2008.

[81] P. Y. Lam, F. Yin, R. T. Hamilton, A. Boveris, and E. Cadenas, "Elevated neuronal nitric oxide synthase expression during ageing and mitochondrial energy production," Free Radical Research, vol. 43, no. 5, pp. 431-439, 2009.

[82] B. P. Tseng, K. N. Green, J. L. Chan, M. Blurton-Jones, and F. M. LaFerla, "A $\beta$ inhibits the proteasome and enhances amyloid and tau accumulation," Neurobiology of Aging, vol. 29, no. 11, pp. 1607-1618, 2008.

[83] M. P. Mattson and T. Magnus, "Ageing and neuronal vulnerability," Nature Reviews Neuroscience, vol. 7, no. 4, pp. 278-294, 2006.

[84] L. P. Yap, J. V. Garcia, D. Han, and E. Cadenas, "The energyredox axis in aging and age-related neurodegeneration," Advanced Drug Delivery Reviews, vol. 61, no. 14, pp. 12831298, 2009.

[85] M. Ziegler, "New functions of a long-known molecule: emerging roles of NAD in cellular signaling," European Journal of Biochemistry, vol. 267, no. 6, pp. 1550-1564, 2000.

[86] A. R. Esteves, J. Lu, M. Rodova et al., "Mitochondrial respiration and respiration-associated proteins in cell lines created through Parkinson's subject mitochondrial transfer," Journal of Neurochemistry, vol. 113, no. 3, pp. 674-682, 2010.

[87] J. D. Adams and L. K. Klaidman, "Sirtuins, nicotinamide and aging: a critical review," Letters in Drug Design and Discovery, vol. 4, no. 1, pp. 44-48, 2007.

[88] K. T. Howitz, K. J. Bitterman, H. Y. Cohen et al., "Small molecule activators of sirtuins extend Saccharomyces cerevisiae lifespan," Nature, vol. 425, no. 6954, pp. 191-196, 2003.

[89] K. L. Mi, JA. K. Soon, M. Poncz, KI. J. Song, and S. P. Kwang, "Resveratrol protects SH-SY5Y neuroblastoma cells from apoptosis induced by dopamine," Experimental and Molecular Medicine, vol. 39, no. 3, pp. 376-384, 2007.

[90] F. Jin, Q. Wu, Y. F. Lu, Q. H. Gong, and J. S. Shi, "Neuroprotective effect of resveratrol on 6-OHDA-induced Parkinson's disease in rats," European Journal of Pharmacology, vol. 600, no. 1-3, pp. 78-82, 2008.

[91] K. T. Lu, M. C. Ko, B. Y. Chen et al., "Neuroprotective effects of resveratrol on MPTP-induced neuron loss mediated by free radical scavenging," Journal of Agricultural and Food Chemistry, vol. 56, no. 16, pp. 6910-6913, 2008.
[92] K. Kakefuda, Y. Fujita, A. Oyagi et al., "Sirtuin 1 overexpression mice show a reference memory deficit, but not neuroprotection," Biochemical and Biophysical Research Communications, vol. 387, no. 4, pp. 784-788, 2009.

[93] M. Pallàs, J. G. Pizarro, J. Gutierrez-Cuesta et al., "Modulation of SIRT1 expression in different neurodegenerative models and human pathologies," Neuroscience, vol. 154, no. 4, pp. 1388-1397, 2008.

[94] N. Maswood, J. Young, E. Tilmont et al., "Caloric restriction increases neurotrophic factor levels and attenuates neurochemical and behavioral deficits in a primate model of Parkinson's disease," Proceedings of the National Academy of Sciences of the United States of America, vol. 101, no. 52, pp. 18171-18176, 2004.

[95] B. J. North, B. L. Marshall, M. T. Borra, J. M. Denu, and E. Verdin, "The human Sir2 ortholog, SIRT2, is an NADdependent tubulin deacetylase," Molecular Cell, vol. 11, no. 2, pp. 437-444, 2003.

[96] T. F. Outeiro, E. Kontopoulos, S. M. Altmann et al., "Sirtuin 2 inhibitors rescue alpha-synuclein-mediated toxicity in models of Parkinson's disease," Science, vol. 317, no. 5837, pp. 516-519, 2007.

[97] M. A. Alim, Q. L. Ma, K. Takeda et al., "Demonstration of a role for $\alpha$-synuclein as a functional microtubule-associated protein," Journal of Alzheimer's Disease, vol. 6, no. 4, pp. 435442, 2004.

[98] A. R. Esteves, D. M. Arduíno, R. H. Swerdlow, C. R. Oliveira, and S. M. Cardoso, "Microtubule depolymerization potentiates alpha-synuclein oligomerization," Frontiers in Ageing Neuroscience, vol. 4, pp. 1-5, 2010.

[99] R. M. Zhou, Y. X. Huang, X. L. Li et al., "Molecular interaction of $\alpha$-synuclein with tubulin influences on the polymerization of microtubule in vitro and structure of microtubule in cells," Molecular Biology Reports, vol. 37, no. 7, pp. 3183-3192, 2009.

[100] P. S. Brookes, Y. Yoon, J. L. Robotham, M. W. Anders, and S. S. Sheu, "Calcium, ATP, and ROS: a mitochondrial love-hate triangle," American Journal of Physiology, vol. 287, no. 4, pp. C817-C833, 2004.

[101] T. B. Sherer, P. A. Trimmer, K. Borland, J. K. Parks, J. P. Bennett, and J. B. Tuttle, "Chronic reduction in complex I function alters calcium signaling in SH-SY5Y neuroblastoma cells," Brain Research, vol. 891, no. 1-2, pp. 94-105, 2001.

[102] J. P. Sheehan, R. H. Swerdlow, W. D. Parker Jr., S. W. Miller, R. E. Davis, and J. B. Tuttle, "Altered calcium homeostasis in cells transformed by mitochondria from individuals with Parkinson's disease," Journal of Neurochemistry, vol. 68, no. 3, pp. 1221-1233, 1997.

[103] A. R. Esteves, D. M. Arduíno, R. H. Swerdlow, C. R. Oliveira, and S. M. Cardoso, "Dysfunctional mitochondria uphold calpain activation: contribution to Parkinson's disease pathology," Neurobiology of Disease, vol. 37, no. 3, pp. 723-730, 2010.

[104] B. M. Ross, N. Mamalias, A. Moszczynska, A. H. Rajput, and S. J. Kish, "Elevated activity of phospholipid biosynthetic enzymes in Substantia nigra of patients with Parkinson's disease," Neuroscience, vol. 102, no. 4, pp. 899-904, 2001.

[105] A. McMahon, B. S. Wong, A. M. Iacopino, M. C. Ng, S. Chi, and D. C. German, "Calbindin-D(28k) buffers intracellular calcium and promotes resistance to degeneration in PC12 cells," Molecular Brain Research, vol. 54, no. 1, pp. 56-63, 1998.

[106] D. C. German, K. F. Manaye, P. K. Sonsalla, and B. A. Brooks, "Midbrain dopaminergic cell loss in Parkinson's disease 
and MPTP-induced Parkinsonismml: sparing of calbindin$\mathrm{D}(28 \mathrm{k})$-containing cells," Annals of the New York Academy of Sciences, vol. 648, pp. 42-62, 1992.

[107] C. L. Liang, C. M. Sinton, P. K. Sonsalla, and D. C. German, "Midbrain dopaminergic neurons in the mouse that contain calbindin-D(28k) exhibit reduced vulnerability to MPTPinduced neurodegeneration," Neurodegeneration, vol. 5, no. 4, pp. 313-318, 1996.

[108] A. Mouatt-Prigent, Y. Agid, and E. C. Hirsch, "Does the calcium binding protein calretinin protect dopaminergic neurons against degeneration in Parkinson's disease?" Brain Research, vol. 668, no. 1-2, pp. 62-70, 1994.

[109] N. T. Hettiarachchi, A. Parker, M. L. Dallas et al., “ $\alpha$ Synuclein modulation of $\mathrm{Ca}^{2+}$ signaling in human neuroblastoma (SH-SY5Y) cells," Journal of Neurochemistry, vol. 111, no. 5, pp. 1192-1201, 2009.

[110] R. L. Morris and P. J. Hollenbeck, "Axonal transport of mitochondria along microtubules and F-actin in living vertebrate neurons," Journal of Cell Biology, vol. 131, no. 5, pp. 1315-1326, 1995.

[111] V. Anesti and L. Scorrano, "The relationship between mitochondrial shape and function and the cytoskeleton," Biochimica et Biophysica Acta, vol. 1757, no. 5-6, pp. 692-699, 2006.

[112] R. H. Wade, "On and around microtubules: an overview," Molecular Biotechnology, vol. 43, no. 2, pp. 177-191, 2009.

[113] M. P. Mattson, W. A. Pedersen, W. Duan, C. Culmsee, and S. Camandola, "Cellular and molecular mechanisms underlying perturbed energy metabolism and neuronal degeneration in Alzheimer's and Parkinson's diseases," Annals of the New York Academy of Sciences, vol. 893, pp. 154-175, 1999.

[114] G. Cappelletti, M. G. Maggioni, and R. Maci, "Influence of MPP on the state of tubulin polymerisation in NGFdifferentiated PC12 cells," Journal of Neuroscience Research, vol. 56, no. 1, pp. 28-35, 1999.

[115] G. Cappelletti, B. Pedrotti, M. G. Maggioni, and R. Maci, "Microtubule assembly is directly affected by MPP in vitro," Cell Biology International, vol. 25, no. 10, pp. 981-984, 2001.

[116] G. Cappelletti, T. Surrey, and R. Maci, "The parkinsonism producing neurotoxin $\mathrm{MPP}+$ affects microtubule dynamics by acting as a destabilising factor," FEBS Letters, vol. 579, no. 21, pp. 4781-4786, 2005.

[117] B. R. Brinkley, S. S. Barham, S. C. Barranco, and G. M. Fuller, "Rotenone inhibition of spindle microtubule assembly in mammalian cells," Experimental Cell Research, vol. 85, no. 1, pp. 41-46, 1974.

[118] L. E. Marshall and R. H. Himes, "Rotenone inhibition of tubulin self-assembly," Biochimica et Biophysica Acta, vol. 543, no. 4, pp. 590-594, 1978.

[119] Y. Ren and J. Feng, "Rotenone selectively kills serotonergic neurons through a microtubule-dependent mechanism," Journal of Neurochemistry, vol. 103, no. 1, pp. 303-311, 2007.

[120] J. Feng, "Microtubule: a common target for Parkin and Parkinson's disease toxins," Neuroscientist, vol. 12, no. 6, pp. 469-476, 2006.

[121] C. Wersinger and A. Sidhu, "Disruption of the interaction of $\alpha$-synuclein with microtubules enhances cell surface recruitment of the dopamine transporter," Biochemistry, vol. 44, no. 41, pp. 13612-13624, 2005.

[122] I. Kim, S. Rodriguez-Enriquez, and J. J. Lemasters, "Selective degradation of mitochondria by mitophagy," Archives of Biochemistry and Biophysics, vol. 462, no. 2, pp. 245-253, 2007.
[123] J. L. Webb, B. Ravikumar, and D. C. Rubinsztein, "Microtubule disruption inhibits autophagosome-lysosome fusion: implications for studying the roles of aggresomes in polyglutamine diseases," International Journal of Biochemistry and Cell Biology, vol. 36, no. 8, pp. 1645-1654, 2004.

[124] B. I. Giasson, M. S. Forman, M. Higuchi et al., "Initiation and synergistic fibrillization of tau and alpha-synuctein," Science, vol. 300, no. 5619, pp. 636-640, 2003.

[125] M. A. Alim, M. S. Hossain, K. Arima et al., "Tubulin seeds $\alpha$-synuclein fibril formation," Journal of Biological Chemistry, vol. 277, no. 3, pp. 2112-2117, 2002.

[126] E. Lindersson, D. Lundvig, C. Petersen et al., "p25 $\alpha$ stimulates $\alpha$-synuclein aggregation and is co-localized with aggregated $\alpha$-synuclein in $\alpha$-synucleinopathies," Journal of Biological Chemistry, vol. 280, no. 7, pp. 5703-5715, 2005.

[127] J. E. Payton, R. J. Perrin, D. F. Clayton, and J. M. George, "Protein-protein interactions of alpha-synuclein in brain homogenates and transfected cells," Molecular Brain Research, vol. 95, no. 1-2, pp. 138-145, 2001.

[128] H. J. Lee, F. Khoshaghideh, S. Lee, and S. J. Lee, "Impairment of microtubule-dependent trafficking by overexpression of $\alpha$ synuclein," European Journal of Neuroscience, vol. 24, no. 11, pp. 3153-3162, 2006.

[129] A. R. Saha, J. Hill, M. A. Utton et al., "Parkinson's disease $\alpha$-synuclein mutations exhibit defective axonal transport in cultured neurons," Journal of Cell Science, vol. 117, no. 7, pp. 1017-1024, 2004.

[130] E. Nogales, "Structural insights into microtubule function," Annual Review of Biochemistry, vol. 69, pp. 277-302, 2000.

[131] K. J. De vos, A. L. Chapman, M. E. Tennant et al., "Familial amyotrophic lateral sclerosis-linked SOD1 mutants perturb fast axonal transport to reduce axonal mitochondria content," Human Molecular Genetics, vol. 16, no. 22, pp. 2720-2728, 2007.

[132] K. E. Miller and M. P. Sheetz, "Axonal mitochondrial transport and potential are correlated," Journal of Cell Science, vol. 117, no. 13, pp. 2791-2804, 2004.

[133] J. Brownlees, S. Ackerley, A. J. Grierson et al., "CharcotMarie-Tooth disease neurofilament mutations disrupt neurofilament assembly and axonal transport," Human Molecular Genetics, vol. 11, no. 23, pp. 2837-2844, 2002.

[134] K. Stamer, R. Vogel, E. Thies, E. Mandelkow, and E. M. Mandelkow, "Tau blocks traffic of organelles, neurofilaments, and APP vesicles in neurons and enhances oxidative stress," Journal of Cell Biology, vol. 156, no. 6, pp. 1051-1063, 2002.

[135] K. J. De Vos, A. J. Grierson, S. Ackerley, and C. C. J. Miller, "Role of axonal transport in neurodegenerative diseases," Annual Review of Neuroscience, vol. 31, pp. 151-173, 2008.

[136] Y. Yoon and M. A. McNiven, "Mitochondrial division: new partners in membrane pinching," Current Biology, vol. 11, no. 2, pp. R67-R70, 2001.

[137] A. Terman, H. Dalen, J. W. Eaton, J. Neuzil, and U. T. Brunk, "Mitochondrial recycling and aging of cardiac myocytes: the role of autophagocytosis," Experimental Gerontology, vol. 38, no. 8, pp. 863-876, 2003.

[138] U. T. Brunk and A. Terman, "Lipofuscin: mechanisms of agerelated accumulation and influence on cell function," Free Radical Biology and Medicine, vol. 33, no. 5, pp. 611-619, 2002.

[139] D. A. Gray and J. Woulfe, "Lipofuscin and ageing: a matter of toxic waste," Science of Aging Knowledge Environment, vol. 5, article no. re1, 2005. 
[140] S. A. Detmer and D. C. Chan, "Functions and dysfunctions of mitochondrial dynamics," Nature Reviews Molecular Cell Biology, vol. 8, no. 11, pp. 870-879, 2007.

[141] A. B. Knott, G. Perkins, R. Schwarzenbacher, and E. BossyWetzel, "Mitochondrial fragmentation in neurodegeneration," Nature Reviews Neuroscience, vol. 9, no. 7, pp. 505-518, 2008.

[142] S. Hoppins, L. Lackner, and J. Nunnari, "The machines that divide and fuse mitochondria," Annual Review of Biochemistry, vol. 76, pp. 751-780, 2007.

[143] K. L. Cerveny, Y. Tamura, Z. Zhang, R. E. Jensen, and H. Sesaki, "Regulation of mitochondrial fusion and division," Trends in Cell Biology, vol. 17, no. 11, pp. 563-569, 2007.

[144] M. J. Barsoum, H. Yuan, A. A. Gerencser et al., "Nitric oxideinduced mitochondrial fission is regulated by dynaminrelated GTPases in neurons," EMBO Journal, vol. 25, no. 16, pp. 3900-3911, 2006.

[145] M. Gomez-Lazaro, N. A. Bonekamp, M. F. Galindo, J. Jordán, and M. Schrader, "6-Hydroxydopamine (6-OHDA) induces Drp1-dependent mitochondrial fragmentation in SH-SY5Y cells," Free Radical Biology and Medicine, vol. 44, no. 11, pp. 1960-1969, 2008.

[146] H. Mortiboys, K. J. Thomas, W. J. H. Koopman et al., "Mitochondrial function and morphology are impaired in parkin-mutant fibroblasts," Annals of Neurology, vol. 64, no. 5, pp. 555-565, 2008.

[147] M. K. Borland, P. A. Trimmer, J. D. Rubinstein et al., "Chronic, low-dose rotenone reproduces lewy neurites found in early stages of Parkinson's disease, reduces mitochondrial movement and slowly kills differentiated SH-SY5Y neural cells," Molecular Neurodegeneration, vol. 3, no. 1, article no. 21, 2008.

[148] A. Weihofen, K. J. Thomas, B. L. Ostaszewski, M. R. Cookson, and D. J. Selkoe, "Pink1 forms a multiprotein complex with miro and milton, linking Pink1 function to mitochondrial trafficking," Biochemistry, vol. 48, no. 9, pp. 2045-2052, 2009.

[149] H. Deng, M. W. Dodson, H. Huang, and M. Guo, "The Parkinson's disease genes pink1 and parkin promote mitochondrial fission and/or inhibit fusion in Drosophila," Proceedings of the National Academy of Sciences of the United States of America, vol. 105, no. 38, pp. 14503-14508, 2008.

[150] A. C. Poole, R. E. Thomas, L. A. Andrews, H. M. McBride, A. J. Whitworth, and L. J. Pallanck, "The PINK1/Parkin pathway regulates mitochondrial morphology," Proceedings of the National Academy of Sciences of the United States of America, vol. 105, no. 5, pp. 1638-1643, 2008.

[151] J. Park, G. Lee, and J. Chung, "The PINK1-Parkin pathway is involved in the regulation of mitochondrial remodeling process," Biochemical and Biophysical Research Communications, vol. 378, no. 3, pp. 518-523, 2009.

[152] N. Exner, B. Treske, D. Paquet et al., "Loss-of-function of human PINK1 results in mitochondrial pathology and can be rescued by parkin," Journal of Neuroscience, vol. 27, no. 45, pp. 12413-12418, 2007.

[153] A. Kathrin Lutz, N. Exner, M. E. Fett et al., "Loss of parkin or PINK1 function increases Drp1-dependent mitochondrial fragmentation," Journal of Biological Chemistry, vol. 284, no. 34, pp. 22938-22951, 2009.

[154] D. Narendra, A. Tanaka, D. F. Suen, and R. J. Youle, "Parkin-induced mitophagy in the pathogenesis of Parkinson disease," Autophagy, vol. 5, no. 5, pp. 706-708, 2009.

[155] S. J. Cherra 3rd, R. K. Dagda, A. Tandon, and C. T. Chu, "Mitochondrial autophagy as a compensatory response to
PINK1 deficiency," Autophagy, vol. 5, no. 8, pp. 1213-1214, 2009.

[156] R. K. Dagda, S. J. Cherra, S. M. Kulich, A. Tandon, D. Park, and C. T. Chu, "Loss of PINK1 function promotes mitophagy through effects on oxidative stress and mitochondrial fission," Journal of Biological Chemistry, vol. 284, no. 20, pp. 13843-13855, 2009.

[157] D. M. Sampathu, B. I. Giasson, A. C. Pawlyk, J. Q. Trojanowski, and V. M. Y. Lee, "Ubiquitination of $\alpha$-synuclein is not required for formation of pathological inclusions in $\alpha$ synucleinopathies," American Journal of Pathology, vol. 163, no. 1, pp. 91-100, 2003.

[158] X. M. Peng, R. Tehranian, P. Dietrich, L. Stefanis, and R. G. Perez, " $\alpha$-synuclein activation of protein phosphatase 2A reduces tyrosine hydroxylase phosphorylation in dopaminergic cells," Journal of Cell Science, vol. 118, no. 15, pp. 35233530, 2005.

[159] R. G. Perez, J. C. Waymire, E. Lin, J. J. Liu, F. Guo, and M. J. Zigmond, "A role for $\alpha$-synuclein in the regulation of dopamine biosynthesis," Journal of Neuroscience, vol. 22, no. 8, pp. 3090-3099, 2002.

[160] A. Iwata, M. Maruyama, I. Kanazawa, and N. Nukina, “ $\alpha$ synuclein affects the MAPK pathway and accelerates cell death," Journal of Biological Chemistry, vol. 276, no. 48, pp. 45320-45329, 2001.

[161] B.-H. Ahn, H. Rhim, S. Y. Kim et al., " $\alpha$-synuclein interacts with phospholipase D isozymes and inhibits pervanadateinduced phospholipase d activation in human embryonic kidney-293 cells," Journal of Biological Chemistry, vol. 277, no. 14, pp. 12334-12342, 2002.

[162] G. S. Withers, J. M. George, G. A. Banker, and D. F. Clayton, "Delayed localization of synelfin (synuclein, NACP) to presynaptic terminals in cultured rat hippocampal neurons," Developmental Brain Research, vol. 99, no. 1, pp. 87-94, 1997.

[163] D. D. Murphy, S. M. Rueter, J. Q. Trojanowski, and V. M. Y. Lee, "Synucleins are developmentally expressed, and $\alpha$ synuclein regulates the size of the presynaptic vesicular pool in primary hippocampal neurons," Journal of Neuroscience, vol. 20, no. 9, pp. 3214-3220, 2000.

[164] D. E. Cabin, K. Shimazu, D. Murphy et al., "Synaptic vesicle depletion correlates with attenuated synaptic responses to prolonged repetitive stimulation in mice lacking $\alpha$ synuclein," Journal of Neuroscience, vol. 22, no. 20, pp. 8797$8807,2002$.

[165] A. Abeliovich, Y. Schmitz, I. Fariñas et al., "Mice lacking $\alpha$-synuclein display functional deficits in the nigrostriatal dopamine system," Neuron, vol. 25, no. 1, pp. 239-252, 2000.

[166] T. D. Kim, E. Choi, H. Rhim, S. R. Paik, and C. H. Yang, “ $\alpha$ synuclein has structural and functional similarities to small heat shock proteins," Biochemical and Biophysical Research Communications, vol. 324, no. 4, pp. 1352-1359, 2004.

[167] N. Ostrerova, L. Petrucelli, M. Farrer et al., " $\alpha$-synuclein shares physical and functional homology with 14-3-3 proteins," Journal of Neuroscience, vol. 19, no. 14, pp. 5782-5791, 1999.

[168] S. Chandra, G. Gallardo, R. Fernández-Chacón, O. M. Schlüter, and T. C. Südhof, "Alpha-synuclein cooperates with CSPalpha in preventing neurodegeneration," Cell, vol. 123, no. 3, pp. 383-396, 2005.

[169] H. Zheng, M. Jiang, M. E. Trumbauer et al., "Mice deficient for the amyloid precursor protein gene," Annals of the New York Academy of Sciences, vol. 777, pp. 421-426, 1996.

[170] E. Masliah, E. Rockenstein, I. Veinbergs et al., "Dopaminergic loss and inclusion body formation in $\alpha$-synuclein mice: 
implications for neurodegenerative disorders," Science, vol. 287, no. 5456, pp. 1265-1269, 2000.

[171] M. Yamada, T. Iwatsubo, Y. Mizuno, and H. Mochizuki, "Overexpression of $\alpha$-synuclein in rat Substantia nigra results in loss of dopaminergic neurons, phosphorylation of $\alpha$-synuclein and activation of caspase-9: resemblance to pathogenetic changes in Parkinson's disease," Journal of Neurochemistry, vol. 91, no. 2, pp. 451-461, 2004.

[172] L. J. Martin, Y. Pan, A. C. Price et al., "Parkinson's disease $\alpha$-synuclein transgenic mice develop neuronal mitochondrial degeneration and cell death," Journal of Neuroscience, vol. 26, no. 1, pp. 41-50, 2006.

[173] J. Li, V. N. Uversky, and A. L. Fink, "Conformational behavior of human $\alpha$-synuclein is modulated by familial Parkinson's disease point mutations A30P and A53T," NeuroToxicology, vol. 23, no. 4-5, pp. 553-567, 2002.

[174] K. A. Conway, J. D. Harper, and P. T. Lansbury, "Accelerated in vitro fibril formation by a mutant $\alpha$-synuclein linked to early-onset Parkinson disease," Nature Medicine, vol. 4, no. 11, pp. 1318-1320, 1998.

[175] K. A. Conway, J. C. Rochet, R. M. Bieganski, and P. T. Lansbury, "Kinetic stabilization of the $\alpha$-synuclein protofibril by a dopamine- $\alpha$-synuclein adduct," Science, vol. 294, no. 5545, pp. 1346-1349, 2001.

[176] E. A. Greenbaum, C. L. Graves, A. J. Mishizen-Eberz et al., "The E46K mutation in $\alpha$-synuclein increases amyloid fibril formation," Journal of Biological Chemistry, vol. 280, no. 9, pp. 7800-7807, 2005.

[177] T. Gomez-Isla, M. C. Irizarry, A. Mariash et al., "Motor dysfunction and gliosis with preserved dopaminergic markers in human $\alpha$-synuclein A30P transgenic mice," Neurobiology of Aging, vol. 24, no. 2, pp. 245-258, 2003.

[178] E. Jo, A. A. Darabie, K. Han, A. Tandon, P. E. Fraser, and J. McLaurin, " $\alpha$-synuclein-synaptosomal membrane interactions Implications for fibrillogenesis," European Journal of Biochemistry, vol. 271, no. 15, pp. 3180-3189, 2004.

[179] A. J. Mishizen-Eberz, R. P. Guttmann, B. I. Giasson et al., "Distinct cleavage patterns of normal and pathologic forms of $\alpha$-synuclein by calpain I in vitro," Journal of Neurochemistry, vol. 86, no. 4, pp. 836-847, 2003.

[180] V. N. Uversky, "Neuropathology, biochemistry, and biophysics of $\alpha$-synuclein aggregation," Journal of Neurochemistry, vol. 103, no. 1, pp. 17-37, 2007.

[181] G. K. Tofaris and M. G. Spillantini, "Physiological and pathological properties of $\alpha$-synuclein," Cellular and Molecular Life Sciences, vol. 64, no. 17, pp. 2194-2201, 2007.

[182] M. M. Tompkins and W. D. Hill, "Contribution of somal Lewy bodies to neuronal death," Brain Research, vol. 775, no. 1-2, pp. 24-29, 1997.

[183] W. Bondareff, C. Q. Mountjoy, M. Roth, and D. L. Hauser, "Neurofibrillary degeneration and neuronal loss in Alzheimer's disease," Neurobiology of Aging, vol. 10, no. 6, pp. 709-715, 1989.

[184] R. Kayed, E. Head, J. L. Thompson et al., "Common structure of soluble amyloid oligomers implies common mechanism of pathogenesis," Science, vol. 300, no. 5618, pp. 486-489, 2003.

[185] M. Bucciantini, E. Giannoni, F. Chiti et al., "Inherent toxicity of aggregates implies a common mechanism for protein misfolding diseases," Nature, vol. 416, no. 6880, pp. 507-511, 2002.

[186] M. J. Volles and P. T. Lansbury, "Vesicle permeabilization by protofibrillar $\alpha$-synuclein is sensitive to Parkinson's diseaselinked mutations and occurs by a pore-like mechanism," Biochemistry, vol. 41, no. 14, pp. 4595-4602, 2002.
[187] M. Zhu, J. Li, and A. L. Fink, "The association of $\alpha$-synuclein with membranes affects bilayer structure, stability, and fibril formation," Journal of Biological Chemistry, vol. 278, no. 41, pp. 40186-40197, 2003.

[188] K. Yamakawa, Y. Izumi, H. Takeuchi et al., "Dopamine facilitates $\alpha$-synuclein oligomerization in human neuroblastoma SH-SY5Y cells," Biochemical and Biophysical Research Communications, vol. 391, no. 1, pp. 129-134, 2010.

[189] C. Follmer, L. Romão, C. M. Einsiedler et al., "Dopamine affects the stability, hydration, and packing of protofibrils and fibrils of the wild type and variants of $\alpha$-synuclein," Biochemistry, vol. 46, no. 2, pp. 472-482, 2007.

[190] M. Wakamatsu, A. Ishii, S. Iwata et al., "Selective loss of nigral dopamine neurons induced by overexpression of truncated human $\alpha$-synuclein in mice," Neurobiology of Aging, vol. 29, no. 4, pp. 574-585, 2008.

[191] M. Periquet, T. Fulga, L. Myllykangas, M. G. Schlossmacher, and M. B. Feany, "Aggregated $\alpha$-synuclein mediates dopaminergic neurotoxicity in vivo," Journal of Neuroscience, vol. 27, no. 12, pp. 3338-3346, 2007.

[192] M. Hashimoto, L. J. Hsu, Y. Xia et al., "Oxidative stress induces amyloid-like aggregate formation of $\mathrm{NACP} / \alpha$ synuclein in vitro," Neuroreport, vol. 10, no. 4, pp. 717-721, 1999.

[193] S. R. Paik, H. J. Shin, and J. H. Lee, "Metal-catalyzed oxidation of $\alpha$-synuclein in the presence of copper(II) and hydrogen peroxide," Archives of Biochemistry and Biophysics, vol. 378, no. 2, pp. 269-277, 2000.

[194] E. Paxinou, Q. Chen, M. Weisse et al., "Induction of $\alpha$-synuclein aggregation by intracellular nitrative insult," Journal of Neuroscience, vol. 21, no. 20, pp. 8053-8061, 2001.

[195] L. Chen, M. Periquet, X. Wang et al., "Tyrosine and serine phosphorylation of $\alpha$-synuclein have opposing effects on neurotoxicity and soluble oligomer formation," Journal of Clinical Investigation, vol. 119, no. 11, pp. 3257-3265, 2009.

[196] S. A. da Silveira, B. L. Schneider, C. Cifuentes-Diaz et al., "Phosphorylation does not prompt, nor prevent, the formation of $\alpha$-synuclein toxic species in a rat model of Parkinson's disease," Human Molecular Genetics, vol. 18, no. 5, pp. 872-887, 2009.

[197] R. Sharon, I. Bar-Joseph, M. P. Frosch, D. M. Walsh, J. A. Hamilton, and D. J. Selkoe, "The formation of highly soluble oligomers of $\alpha$-synuclein is regulated by fatty acids and enhanced in Parkinson's disease," Neuron, vol. 37, no. 4, pp. 583-595, 2003.

[198] M. Matsuzaki, T. Hasegawa, A. Takeda et al., "Histochemical features of stress-induced aggregates in $\alpha$-synuclein overexpressing cells," Brain Research, vol. 1004, no. 1-2, pp. 83-90, 2004.

[199] H.-J. Lee, S. Y. Shin, C. Choi, Y. H. Lee, and S.-J. Lee, "Formation and removal of $\alpha$-synuclein aggregates in cells exposed to mitochondrial inhibitors," Journal of Biological Chemistry, vol. 277, no. 7, pp. 5411-5417, 2002.

[200] H. Elkon, J. Don, E. Melamed, I. Ziv, A. Shirvan, and D. Offen, "Mutant and wild-type $\alpha$-synuclein interact with mitochondrial cytochrome C oxidase," Journal of Molecular Neuroscience, vol. 18, no. 3, pp. 229-238, 2002.

[201] W. W. Li, R. Yang, J. C. Guo et al., "Localization of $\alpha$-synuclein to mitochondria within midbrain of mice," Neuroreport, vol. 18, no. 15, pp. 1543-1546, 2007.

[202] S. Shavali, H. M. Brown-Borg, M. Ebadi, and J. Porter, "Mitochondrial localization of alpha-synuclein protein in alpha-synuclein overexpressing cells," Neuroscience Letters, vol. 439 , no. 2 , pp. 125-128, 2008. 
[203] L. Devi, V. Raghavendran, B. M. Prabhu, N. G. Avadhani, and H. K. Anandatheerthavarada, "Mitochondrial import and accumulation of $\alpha$-synuclein impair complex I in human dopaminergic neuronal cultures and Parkinson disease brain," Journal of Biological Chemistry, vol. 283, no. 14, pp. 9089-9100, 2008.

[204] S. Büttner, A. Bitto, J. Ring et al., "Functional mitochondria are required for $\alpha$-synuclein toxicity in aging yeast," Journal of Biological Chemistry, vol. 283, no. 12, pp. 7554-7560, 2008.

[205] D. M. Arduíno, A. R. Esteves, C. R. Oliveira, and S. M. Cardoso, "Mitochondrial metabolism modulation: a new therapeutic approach for Parkinson's disease," CNS and Neurological Disorders, vol. 9, no. 1, pp. 105-119, 2010.

[206] A. F. Domingues, A. R. F. Esteves, R. H. Swerdlow, C. R. Oliveira, and S. M. Cardoso, "Calpain-mediated MPP toxicity in mitochondrial DNA depleted cells," Neurotoxicity Research, vol. 13, no. 1, pp. 31-38, 2008.

[207] H. Sorimachi, S. Ishiura, and K. Suzuki, "Structure and physiological function of calpains," Biochemical Journal, vol. 328, no. 3, pp. 721-732, 1997.

[208] D. E. Goll, V. F. Thompson, H. Li, W. Wei, and J. Cong, "The calpain system," Physiological Reviews, vol. 83, no. 3, pp. 731801, 2003.

[209] Y. Emori, H. Kawasaki, S. Imajoh, Y. Minami, and K. Suzuki, "All four repeating domains of the endogenous inhibitor for calcium-dependent protease independently retain inhibitory activity. Expression of the cDNA fragments in Escherichia coli," Journal of Biological Chemistry, vol. 263, no. 5, pp. 23642370, 1988.

[210] K. Suzuki, S. Imajoh, Y. Emori, H. Kawasaki, Y. Minami, and S. Ohno, "Calcium-activated neutral protease and its endogenous inhibitor. Activation at the cell membrane and biological function," FEBS Letters, vol. 220, no. 2, pp. 271277, 1987.

[211] M. Isabella Pörn-Ares, A. Samali, and S. Orrenius, "Cleavage of the calpain inhibitor, calpastatin, during apoptosis," Cell Death and Differentiation, vol. 5, no. 12, pp. 1028-1033, 1998.

[212] B. T. Chua, K. Guo, and P. Li, "Direct cleavage by the calcium-activated protease calpain can lead to inactivation of caspases," Journal of Biological Chemistry, vol. 275, no. 7, pp. 5131-5135, 2000.

[213] A. K. F. Liou, Z. Zhou, W. Pei, T. M. Lim, X. M. Yin, and J. Chen, "BimEL up-regulation potentiates AIF translocation and cell death in response to MPTP," FASEB Journal, vol. 19, no. 10, pp. 1350-1352, 2005.

[214] G. N. Patrick, L. Zukerberg, M. Nikolic, S. De La Monte, P. Dikkes, and L. H. Tsai, "Conversion of p35 to p25 deregulates Cdk5 activity and promotes neurodegeneration," Nature, vol. 402, no. 6762, pp. 615-622, 1999.

[215] G. I. Kusakawa, T. Saito, R. Onuki, K. Ishiguro, T. Kishimoto, and S. I. Hisanaga, "Calpain-dependent proteolytic cleavage of the p35 cyclin-dependent kinase 5 activator to p25," Journal of Biological Chemistry, vol. 275, no. 22, pp. 1716617172,2000

[216] P. D. Smith, S. J. Crocker, V. Jackson-Lewis et al., "Cyclindependent kinase 5 is a mediator of dopaminergic neuron loss in a mouse model of Parkinson's disease," Proceedings of the National Academy of Sciences of the United States of America, vol. 100, no. 23, pp. 13650-13655, 2003.

[217] A. Mouatt-Prigent, J. O. Karlsson, Y. Agid, and E. C. Hirsch, "Increased M-calpain expression in the mesencephalon of patients with Parkinson's disease but not in other neurodegenerative disorders involving the mesencephalon: a role in nerve cell death?" Neuroscience, vol. 73, no. 4, pp. 979-987, 1996.

[218] B. Chera, K. E. Schaecher, A. Rocchini et al., "Immunofluorescent labeling of increased calpain expression and neuronal death in the spinal cord of 1-methyl-4-phenyl-1,2,3,6tetrahydropyridine- treated mice," Brain Research, vol. 1006, no. 2, pp. 150-156, 2004.

[219] S. J. Crocker, P. D. Smith, V. Jackson-Lewis et al., "Inhibition of calpains prevents neuronal and behavioral deficits in an MPTP mouse model of Parkinson's disease," Journal of Neuroscience, vol. 23, no. 10, pp. 4081-4091, 2003.

[220] M. Chen, H. He, S. Zhan, S. Krajewski, J. C. Reed, and R. A. Gottlieb, "Bid is cleaved by calpain to an active fragment in vitro and during myocardial ischemia/reperfusion," Journal of Biological Chemistry, vol. 276, no. 33, pp. 30724-30728, 2001.

[221] M. J. Chen, Y. W. Yap, M. S. Choy et al., "Early induction of calpains in rotenone-mediated neuronal apoptosis," Neuroscience Letters, vol. 397, no. 1-2, pp. 69-73, 2006.

[222] S. Samantaray, V. H. Knaryan, M. K. Guyton, D. D. Matzelle, S. K. Ray, and N. L. Banik, "The parkinsonian neurotoxin rotenone activates calpain and caspase-3 leading to motoneuron degeneration in spinal cord of Lewis rats," Neuroscience, vol. 146, no. 2, pp. 741-755, 2007.

[223] A. Haacke, F. U. Hartl, and P. Breuer, "Calpain inhibition is sufficient to suppress aggregation of polyglutamineexpanded ataxin-3," Journal of Biological Chemistry, vol. 282, no. 26, pp. 18851-18856, 2007.

[224] P. Goñi-Oliver, J. J. Lucas, J. Avila, and F. Hernández, "Nterminal cleavage of GSK-3 by calpain: a new form of GSK-3 regulation," Journal of Biological Chemistry, vol. 282, no. 31, pp. 22406-22413, 2007.

[225] S. J. Kim, J. Y. Sung, J. W. Um et al., "Parkin cleaves intracellular $\alpha$-synuclein inclusions via the activation of calpain," Journal of Biological Chemistry, vol. 278, no. 43, pp. 41890-41899, 2003.

[226] A. J. Mishizen-Eberz, E. H. Norris, B. I. Giasson et al., "Cleavage of $\alpha$-synuclein by calpain: potential role in degradation of fibrillized and nitrated species of $\alpha$-synuclein," Biochemistry, vol. 44, no. 21, pp. 7818-7829, 2005.

[227] B. M. Dufty, L. R. Warner, S. T. Hou et al., "Calpain-cleavage of $\alpha$-synuclein: connecting proteolytic processing to diseaselinked aggregation," American Journal of Pathology, vol. 170, no. 5, pp. 1725-1738, 2007.

[228] F. Demarchi, C. Bertoli, T. Copetti et al., "Calpain is required for macroautophagy in mammalian cells," Journal of Cell Biology, vol. 175, no. 4, pp. 595-605, 2006.

[229] J. Y. Zhang, C. Peng, H. Shi, S. Wang, Q. Wang, and J. Z. Wang, "Inhibition of autophagy causes tau proteolysis by activating calpain in rat brain," Journal of Alzheimer's Disease, vol. 16, no. 1, pp. 39-47, 2009.

[230] E. R. Stadtman, "Protein oxidation in aging and age-related diseases," Annals of the New York Academy of Sciences, vol. 928, pp. 22-38, 2001.

[231] C. He and D. J. Klionsky, "Regulation mechanisms and signaling pathways of autophagy," Annual Review of Genetics, vol. 43, pp. 67-93, 2009.

[232] A. M. Cuervo, A. Palmer, A. J. Rivett, and E. Knecht, "Degradation of proteasomes by lysosomes in rat liver," European Journal of Biochemistry, vol. 227, no. 3, pp. 792800, 1995.

[233] A. M. Cuervo, "Autophagy: many paths to the same end," Molecular and Cellular Biochemistry, vol. 263, no. 1, pp. 55$72,2004$. 
[234] T. Yorimitsu and D. J. Klionsky, "Autophagy: molecular machinery for self-eating," Cell Death and Differentiation, vol. 12, supplement 2, pp. 1542-1552, 2005.

[235] A. J. Meijer and P. Codogno, "Regulation and role of autophagy in mammalian cells," International Journal of Biochemistry and Cell Biology, vol. 36, no. 12, pp. 2445-2462, 2004.

[236] N. Mizushima, B. Levine, A. M. Cuervo, and D. J. Klionsky, "Autophagy fights disease through cellular self-digestion," Nature, vol. 451, no. 7182, pp. 1069-1075, 2008.

[237] B. Levine and D. J. Klionsky, "Development by selfdigestion: molecular mechanisms and biological functions of autophagy," Developmental Cell, vol. 6, no. 4, pp. 463-477, 2004.

[238] B. Levine, "Eating oneself and uninvited guests: autophagyrelated pathways in cellular defense," Cell, vol. 120, no. 2, pp. 159-162, 2005.

[239] J. P. Luzio, V. Poupon, M. R. Lindsay, B. M. Mullock, R. C. Piper, and P. R. Pryor, "Membrane dynamics and the biogenesis of lysosomes," Molecular Membrane Biology, vol. 20, no. 2, pp. 141-154, 2003.

[240] L. Marzella, J. Ahlberg, and H. Glaumann, "Autophagy, heterophagy, microautophagy and crinophagy as the means for intracellular degradation," Virchows Archiv Abteilung B, vol. 36, no. 2-3, pp. 219-234, 1981.

[241] D. J. Klionsky, "The molecular machinery of autophagy: unanswered questions," Journal of Cell Science, vol. 118, no. 1, pp. 7-18, 2005.

[242] J. F. Dice, S. R. Terlecky, H. L. Chiang et al., "A selective pathway for degradation of cytosolic proteins by lysosomes," Seminars in Cell Biology, vol. 1, no. 6, pp. 449-455, 1990.

[243] P. Anglade, "Apoptosis and autophagy in nigral neurons of patients with Parkinson's disease," Histology and Histopathology, vol. 12, no. 1, pp. 25-31, 1997.

[244] F. Fornai, P. Lenzi, M. Gesi et al., "Methamphetamine produces neuronal inclusions in the nigrostriatal system and in PC12 cells," Journal of Neurochemistry, vol. 88, no. 1, pp. 114-123, 2004.

[245] H. J. Rideout, I. Lang-Rollin, and L. Stefanis, "Involvement of macroautophagy in the dissolution of neuronal inclusions," International Journal of Biochemistry and Cell Biology, vol. 36, no. 12, pp. 2551-2562, 2004.

[246] W. H. Yu, B. Dorado, H. Y. Figueroa et al., "Metabolic activity determines efficacy of macroautophagic clearance of pathological oligomeric $\alpha$-synuclein," American Journal of Pathology, vol. 175, no. 2, pp. 736-747, 2009.

[247] Y. Chu, H. Dodiya, P. Aebischer, C. W. Olanow, and J. H. Kordower, "Alterations in lysosomal and proteasomal markers in Parkinson's disease: relationship to alpha-synuclein inclusions," Neurobiology of Disease, vol. 35, no. 3, pp. 385398, 2009.

[248] U. Bandhyopadhyay and A. M. Cuervo, "Chaperonemediated autophagy in ageing and neurodegeneration: lessons from alpha-synuclein," Experimental Gerontology, vol. 42, no. 1-2, pp. 120-128, 2007.

[249] B. Ravikumar, R. Duden, and D. C. Rubinsztein, "Aggregateprone proteins with polyglutamine and polyalanine expansions are degraded by autophagy," Human Molecular Genetics, vol. 11, no. 9, pp. 1107-1117, 2002.

[250] B. Ravikumar and D. C. Rubinsztein, "Can autophagy protect against neurodegeneration caused by aggregate-prone proteins?" Neuroreport, vol. 15, no. 16, pp. 2443-2445, 2004.

[251] J. L. Webb, B. Ravikumar, J. Atkins, J. N. Skepper, and D. C. Rubinsztein, " $\alpha$-synuclein is degraded by both autophagy and the proteasome," Journal of Biological Chemistry, vol. 278, no. 27, pp. 25009-25013, 2003.

[252] T. Vogiatzi, M. Xilouri, K. Vekrellis, and L. Stefanis, "Wild type $\alpha$-synuclein is degraded by chaperone-mediated autophagy and macroautophagy in neuronal cells," Journal of Biological Chemistry, vol. 283, no. 35, pp. 23542-23556, 2008.

[253] A. M. Cuervo, L. Stafanis, R. Fredenburg, P. T. Lansbury, and D. Sulzer, "Impaired degradation of mutant $\alpha$-synuclein by chaperone-mediated autophagy," Science, vol. 305, no. 5688, pp. 1292-1295, 2004.

[254] M. Martinez-Vicente, Z. Talloczy, S. Kaushik et al., "Dopamine-modified $\alpha$-synuclein blocks chaperonemediated autophagy," Journal of Clinical Investigation, vol. 118, no. 2, pp. 777-778, 2008.

[255] T. Nonaka and M. Hasegawa, "A cellular model to monitor proteasome dysfunction by $\alpha$-synuclein," Biochemistry, vol. 48, no. 33, pp. 8014-8022, 2009.

[256] L. Stefanis, K. E. Larsen, H. J. Rideout, D. Sulzer, and L. A. Greene, "Expression of A53T mutant but not wild-type $\alpha$ synuclein in PC12 cells induces alterations of the ubiquitindependent degradation system, loss of dopamine release, and autophagic cell death," Journal of Neuroscience, vol. 21, no. 24, pp. 9549-9560, 2001.

[257] D. J. Klionsky and S. D. Emr, "Autophagy as a regulated pathway of cellular degradation," Science, vol. 290, no. 5497, pp. 1717-1721, 2000.

[258] B. Spencer, R. Potkar, M. Trejo et al., "Beclin 1 gene transfer activates autophagy and ameliorates the neurodegenerative pathology in $\alpha$-synuclein models of Parkinson's and Lewy body diseases," Journal of Neuroscience, vol. 29, no. 43, pp. 13578-13588, 2009.

[259] M. Ermini, "Ageing changes in mammalian skeletal muscle; biochemical studies," Gerontology, vol. 22, no. 4, pp. 301-316, 1976.

[260] E. Beregi, O. Regius, T. Huttl, and Z. Gobl, "Age-related changes in the skeletal muscle cells," Zeitschrift fur Gerontologie, vol. 21, no. 2, pp. 83-86, 1988.

[261] V. A. Bohr, "Repair of oxidative DNA damage in nuclear and mitochondrial DNA, and some changes with aging in mammalian cells," Free Radical Biology and Medicine, vol. 32, no. 9, pp. 804-812, 2002.

[262] K. Takeshige, M. Baba, S. Tsuboi, T. Noda, and Y. Ohsumi, "Autophagy in yeast demonstrated with proteinase-deficient mutants and conditions for its induction," Journal of Cell Biology, vol. 119, no. 2, pp. 301-312, 1992.

[263] H. Takano-Ohmuro, M. Mukaida, E. Kominami, and K. Morioka, "Autophagy in embryonic erythroid cells: its role in maturation," European Journal of Cell Biology, vol. 79, no. 10, pp. 759-764, 2000.

[264] G. E. Mortimore, G. Miotto, R. Venerando, and M. Kadowaki, "Autophagy," Sub-Cellular Biochemistry, vol. 27, pp. 93-135, 1996.

[265] I. Kissová, M. Deffieu, S. Manon, and N. Camougrand, "Uth1p is involved in the autophagic degradation of mitochondria," Journal of Biological Chemistry, vol. 279, no. 37, pp. 39068-39074, 2004.

[266] C. T. Chu, J. Zhu, and R. Dagda, "Beclin 1-independent pathway of damage-induced mitophagy and autophagic stress: implications for neurodegeneration and cell death," Autophagy, vol. 3, no. 6, pp. 663-666, 2007.

[267] S. Michiorri, V. Gelmetti, E. Giarda et al., "The Parkinsonassociated protein PINK1 interacts with Beclin1 and promotes autophagy," Cell Death and Differentiation, vol. 17, no. 6, pp. 962-974, 2010. 
[268] S. Geisler, K. M. Holmström, D. Skujat et al., "PINK1/Parkinmediated mitophagy is dependent on VDAC1 and p62/SQSTM1," Nature Cell Biology, vol. 12, no. 2, pp. 119-131, 2010.

[269] A. C. Belin and M. Westerlund, "Parkinson's disease: a genetic perspective,” FEBS Journal, vol. 275, no. 7, pp. 1377-1383, 2008. 


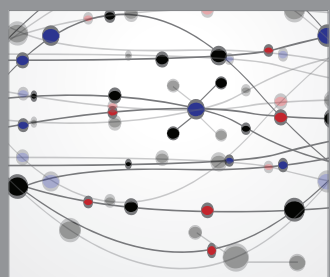

The Scientific World Journal
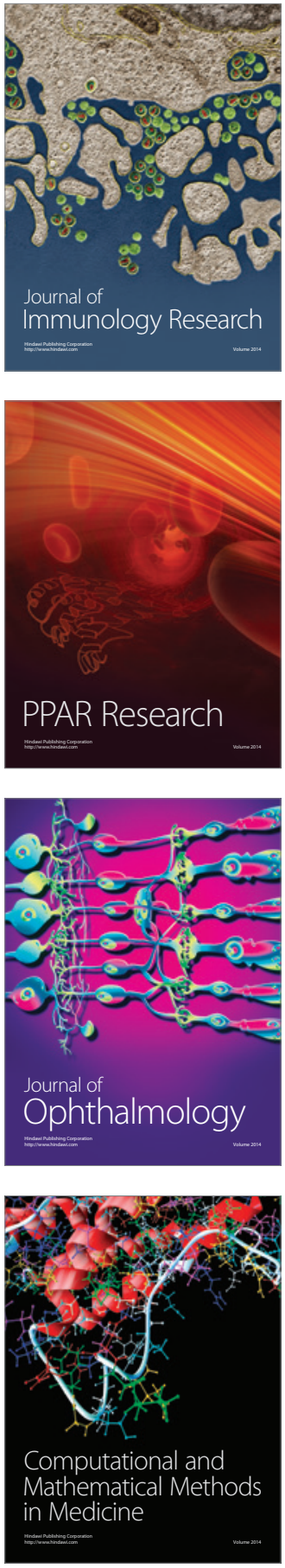

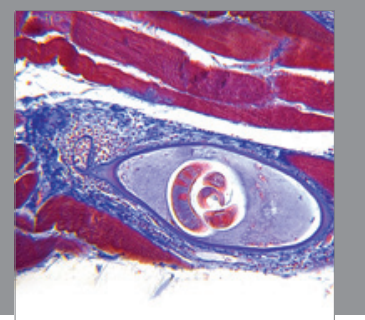

Gastroenterology

Research and Practice
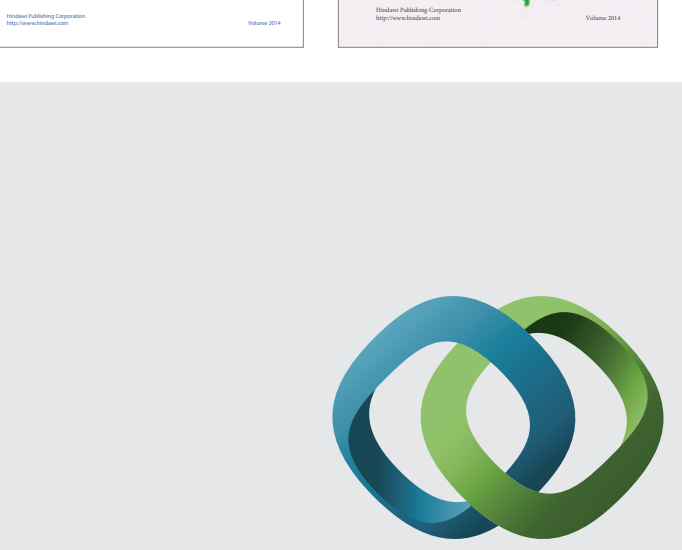

\section{Hindawi}

Submit your manuscripts at

http://www.hindawi.com
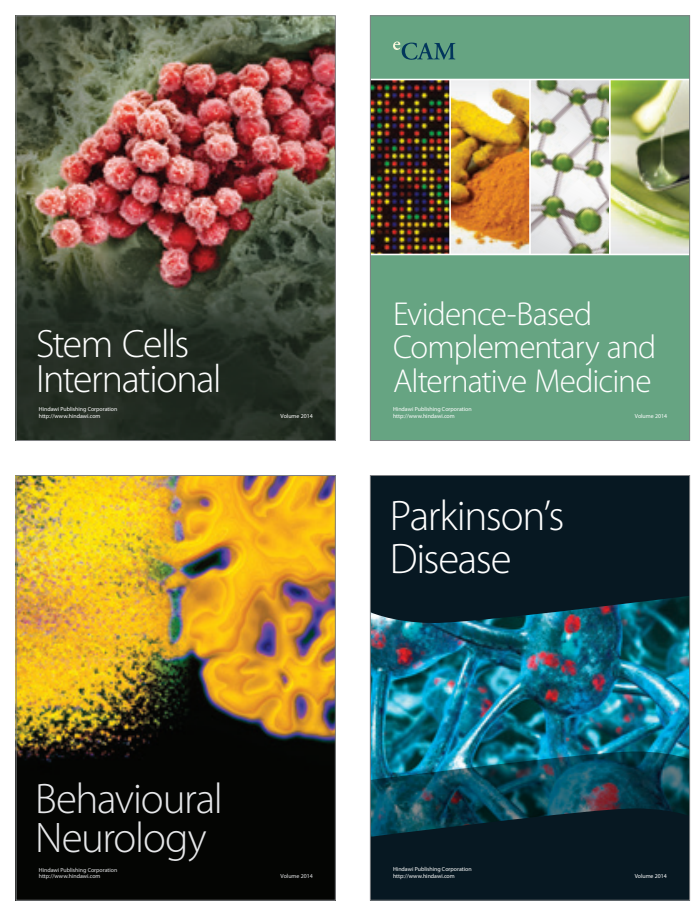

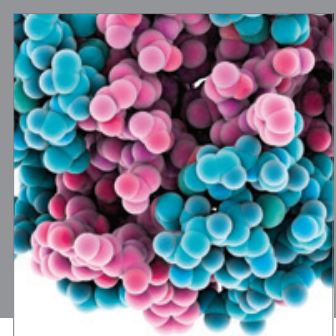

Journal of
Diabetes Research

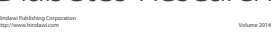

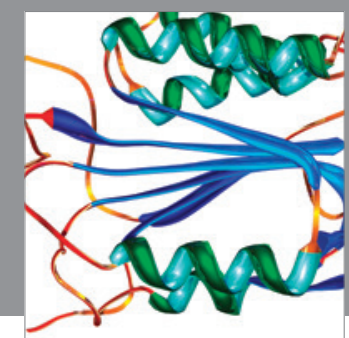

Disease Markers
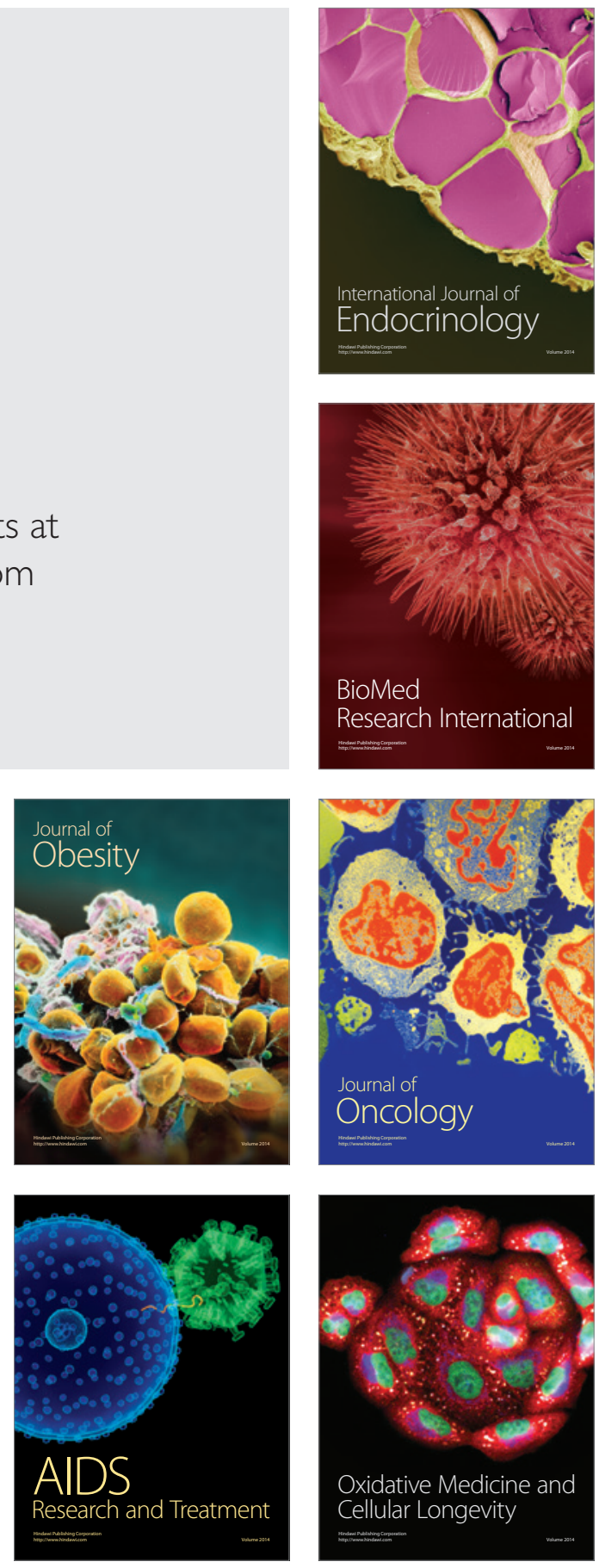